\title{
THE GROWTH AND ORGANIZATION OF THE OPTIC NERVE AND TRACT IN JUVENILE AND ADULT GOLDFISH ${ }^{1}$
}

\author{
STEPHEN S. EASTER, JR., ${ }^{2}$ ANNE C. RUSOFF, ${ }^{3}$ AND PHILLIP E. KISH ${ }^{4}$ \\ Division of Biological Sciences, The University of Michigan, Ann Arbor, Michigan 48104
}

\begin{abstract}
The optic nerves, tracts, and tecta of goldfish, 1 to 5 years old, have been studied anatomically using light and electron microscopy, horseradish peroxidase (HRP), and tritiated proline radioautography. The aims were to document an earlier inference that fibers are added to the nerve continually and to describe the growth and organization of the pathway.

(1) The numbers of optic fibers were counted in electron micrographs of the nerve. There were about $120,000,165,000$, and 180,000 in 1-, 3-, and 5-year-old fish, respectively.

(2) In young fish, there are a few thousand nonmyelinated fibers which exit the retina together and cluster together in the nerve and tract. When the axons of only the newest (peripheral) ganglion cells were cut intraretinally, fibers in and around the bundles of nonmyelinated fibers degenerated. The nonmyelinated fibers are, therefore, the new ones.

(3) Fibers from ventral or dorsal hemiretinas were backfilled selectively with HRP introduced into one of the brachia of the optic tract. Behind the optic papilla, where the cross-section of the optic nerve was trapezoidal, the new fibers were found in a strip along the narrow base of the trapezoid. The dorsal retinal fibers formed the central trapezoid and the ventral fibers formed the two flanking zones. Closer to the brain, the fibers from the two hemiretinas intermingled before being segregated again at the origin of the brachia.

(4) Small groups of ganglion cells were labeled by intraretinal injection of HRP and their fibers were traced in sections of the nerve and tract. The labeled fibers were clustered, but the positions of the fibers in the cross-section of the nerve were defined less precisely than the positions of the somata in the retina.

(5) Hemisection of the nerve in the orbit, followed by intraocular injection of tritiated proline, produced radioautographs with an unlabeled annular zone of tectum. Since the retina projects topographically to the tectum, the severed fibers must have originated from an annular region of the retina.

We infer that new fibers are added to the nerve continually and that the retinal origins of fibers are correlated with their positions in the cross-section of the nerve. These rules of order change with distance from the retina; the strict order at the optic papilla changes gradually to an equally strict, but different, order at the level of the brachia.
\end{abstract}

The retina of the teleost fish is unusual among vertebrate nervous systems in that it continues to add new neurons for years, throughout much of the animal's life. This neurogenesis occurs at the extreme retinal margin

\footnotetext{
' This work was supported by Research Grant EY-00168 to S. S. E. A. C. R. was supported by Postdoctoral Fellowship EY-05294. We thank Dr. Pamela R. Johns for useful discussions and comments on the paper and Mr. Steven Scherer for early technical assistance.

${ }^{2}$ To whom correspondence should be addressed at Division of Biological Sciences, 2109 Natural Science Building, The University of Michigan. Ann Arbor, MI 48109.

${ }^{3}$ Present address: Department of Physiological Sciences, School of Veterinary Medicine, Oklahoma State University, Stillwater, OK 74078.

${ }^{4}$ Present address: Instilute of Experimental Pathology and Toxicology, Albany Medical College, Albany, NY 12208.
}

in a remnant population of neuroepithelial cells. After a cell completes its terminal mitotic division, it remains in place and differentiates, while sister cells continue to proliferate along the new margin, peripheral to the old. Thus, cells are added in annuli approximately centered on the optic disc: the more peripheral the retinal position, the younger the cells (Müller, 1952; Johns and Easter, 1977; Johns, 1977; Meyer, 1978).

Recently, two of us showed that a small amount of horseradish peroxidase (HRP) injected into the nerve was transported retrogradely by a group of neighboring axons to ganglion cells in an annular region of the retina (Rusoff and Easter, 1980). We interpreted this in the context of retinal growth. We suggested, as Scholes (1979) had done before, that the growing axons of the new 
ganglion cells clustered together in the nerve and remained together as the animal aged. If this interpretation is correct, then three predictions follow. (1) The new fibers ought to be clustered together and should be recognizable by a lack of myelin. (2) Older fish should have more optic nerve fibers than young ones. (3) Discrete lesions in the nerve ought to interrupt axons from an annular region of retina.

In this report, we describe the nerve in more detail than had been available previously and test the three predictions above. In addition, we include observations relevant to the issue of the topographic order of fibers in the nerve, a subject of considerable recent interest (Bodick and Levinthal, 1980; Bunt and Horder, 1978; Dawnay, 1979a, b; Gaze and Grant, 1978; Horder and Martin, 1978; Horton et al., 1979; Levinthal and Levinthal, 1980; Mason et al., 1979; Rusoff, 1979; Rusoff and Easter, 1979, 1980; Scholes, 1979).

\section{Materials and Methods}

Goldfish (common strain) were obtained commercially (Grassy Forks Fisheries, Martinsville, IN), maintained in aerated aquaria, fed daily, and generally killed within a few weeks after arriving in Ann Arbor.

Tissue preparation for electron microscopy. The fish was anesthetized in an aqueous solution of tricaine methanesulfonate, the aorta was severed, and one or both orbits and the cranial cavity were exposed dorsally. The head then was cut off and immersed in a prefixative (3.2\% glutaraldehyde, $3.0 \%$ paraformaldehyde, $0.1 \%$ picric acid, 1.0\% dimethyl sulfoxide (DMSO), $0.001 \mathrm{M} \mathrm{CaCl}_{2}, 0.1$ M sodium cacodylate buffer, $\mathrm{pH} 7.2$ to 7.4 ) at room temperature for $1 \mathrm{hr}$. The eye was opened, the lens was removed, its diameter was measured, and the optic nerve was dissected free, usually with a fragment of the eye attached. In some cases, the entire optic nerve and tract were dissected out while still attached to fragments of the eye and the brain. The tissue then was immersed in fresh prefixative for another hour, rinsed in several changes of buffer (3.4\% sucrose, $0.001 \mathbf{M ~ C a C l}_{2}, 0.1 \mathbf{~}$ sodium cacodylate buffer, $\mathrm{pH}=7.2$ to 7.4 ), postfixed for $6 \mathrm{hr}$ in buffered osmium tetroxide (2\% osmium tetroxide, $0.001 \mathrm{M} \mathrm{CaCl}_{2}, 0.1 \mathrm{M}$ sodium cacodylate buffer, $\mathrm{pH} 7.2$ to 7.4), and stained overnight in maleate-buffered uranyl acetate (Karnovsky, 1967). It was dehydrated in ethanol, cleared in propylene oxide, and embedded in Epon. Semithin sections ( 1 to $2 \mu \mathrm{m}$ thick) were stained with toluidine blue and examined light microscopically. Thin sections (silver to gold interference colors) were stained with uranyl acetate and lead citrate, mounted on a Formvarcoated one-hole grid, and examined in a Philips 300 electron microscope.

Estimation of numbers of optic fibers. A transverse section through an entire nerve was photographed at low magnification on the electron microscope. Then, the resultant prints were used to construct a photomosaic of the section (magnification: $\times 574$ to 1,300 ) (Fig. $1 A$ ) which then was traced to show the outlines of the bundles of nerve fibers (Fig. $1 B$ ). Any region more than about 20 $\mu \mathrm{m}$ wide which contained no fibers was excluded from the tracings. These outlines then were traced on a digitizing tablet linked to a digital computer which computed the cross-sectional areas of the various bundles. Next, 30 to 90 sites (dots on Fig. $1 B$ ) were photographed at higher magnification on the same section. Individual myelinated fibers (mean number per nerve, 6,861) were counted from the resultant prints (magnification: $\times 13,980$ to 26,247 ), and a mean planimetric density of myelinated nerve fibers was computed for each bundle. Those bundles which had not been sampled at high magnification were assigned the mean planimetric density of the two nearest bundles. The planimetric density multiplied by the crosssectional area of a bundle gave the number of fibers per bundle, and the sum of the fibers computed in all bundles gave the total number in the nerve. Nonmyelinated fibers, restricted to a few percent of the total cross-section, were estimated similarly but at two higher magnifications ( $\times 8,100$ and 67,000). Magnifications were obtained from calibration standards which were photographed at the same magnifications as the nerves. For low magnifications, a 400-mesh grid was used; for high magnifications, a grating replica $(2,160$ lines $/ \mathrm{mm})$ was the standard.

As a check on the reliability of the method, one nerve was counted at three levels, hundreds of micrometers apart. The estimates were very similar; the standard deviation was less than $3 \%$ of the mean.

HRP methods. HRP (Miles, $30 \%$ in $2 \%$ aqueous DMSO) was applied to severed fibers in the retina or optic tract as described under "Results." Then, the fish was returned to an aquarium and maintained at 16 to $18^{\circ} \mathrm{C}$ for a length of time which varied with the size of the fish and the site of HRP administration. Next, it was anesthetized and killed either by perfusion with fixative ( $2 \%$ glutaraldehyde in phosphate buffer, $\mathrm{pH} 7.4$ ) or by decapitation. Perfusion often caused the neural retina to adhere to the retinal pigmented epithelium; this was undesirable when the retina was to be mounted whole; therefore, decapitation was used most often. The optic tract, nerve, and eyecup were removed intact and placed in fixative. The nonretinal parts of the eyecup were removed as soon as possible, leaving the retina attached to the nerve. Tissue remained in the fixative at room temperature for at least $2 \mathrm{hr}$. Then, the retina was severed from the nerve and whole mounted, photoreceptor side down, on a freshly gelatinized slide and secured in place with a piece of Telfa gauze (Stell and Witkovsky, 1973). The tissue then was rinsed overnight in phosphate buffer plus $30 \mathrm{gm}$ of sucrose $/ 100 \mathrm{ml}$ of solution in the refrigerator. The optic nerve and tract were embedded in a mixture of $10 \%$ gelatin plus $30 \mathrm{gm}$ of sucrose $/ 100 \mathrm{ml}$ of solution; blocks were hardened overnight in $2 \%$ glutaraldehyde in phosphate buffer plus $30 \mathrm{gm}$ of sucrose $100 \mathrm{ml}$ of solution and sectioned in a cryostat at $40 \mu \mathrm{m}$. Each section was mounted immediately on a chrome alumsubbed slide; alternate sections were placed on another slide so that they could be embedded in Fpon and resectioned. Sections were dried onto the slides and then processed to reveal the HRP. Processing included pretreatment in $10 \% \mathrm{CoCl}_{2}$ for $20 \mathrm{~min}$, incubation in $o$ dianisidine $(45 \mathrm{mg} / 150 \mathrm{ml}$ of phosphate buffer plus $1 \%$ DMSO) for $20 \mathrm{~min}$, and finally reaction in the incubation mixture plus $5 \mathrm{ml}$ of $1.2 \% \mathrm{H}_{2} \mathrm{O}_{2} / 150 \mathrm{ml}$ of solution (R. G. Northcutt, personal communication.) Sections then were rinsed in distilled water and counterstained with cresyl 


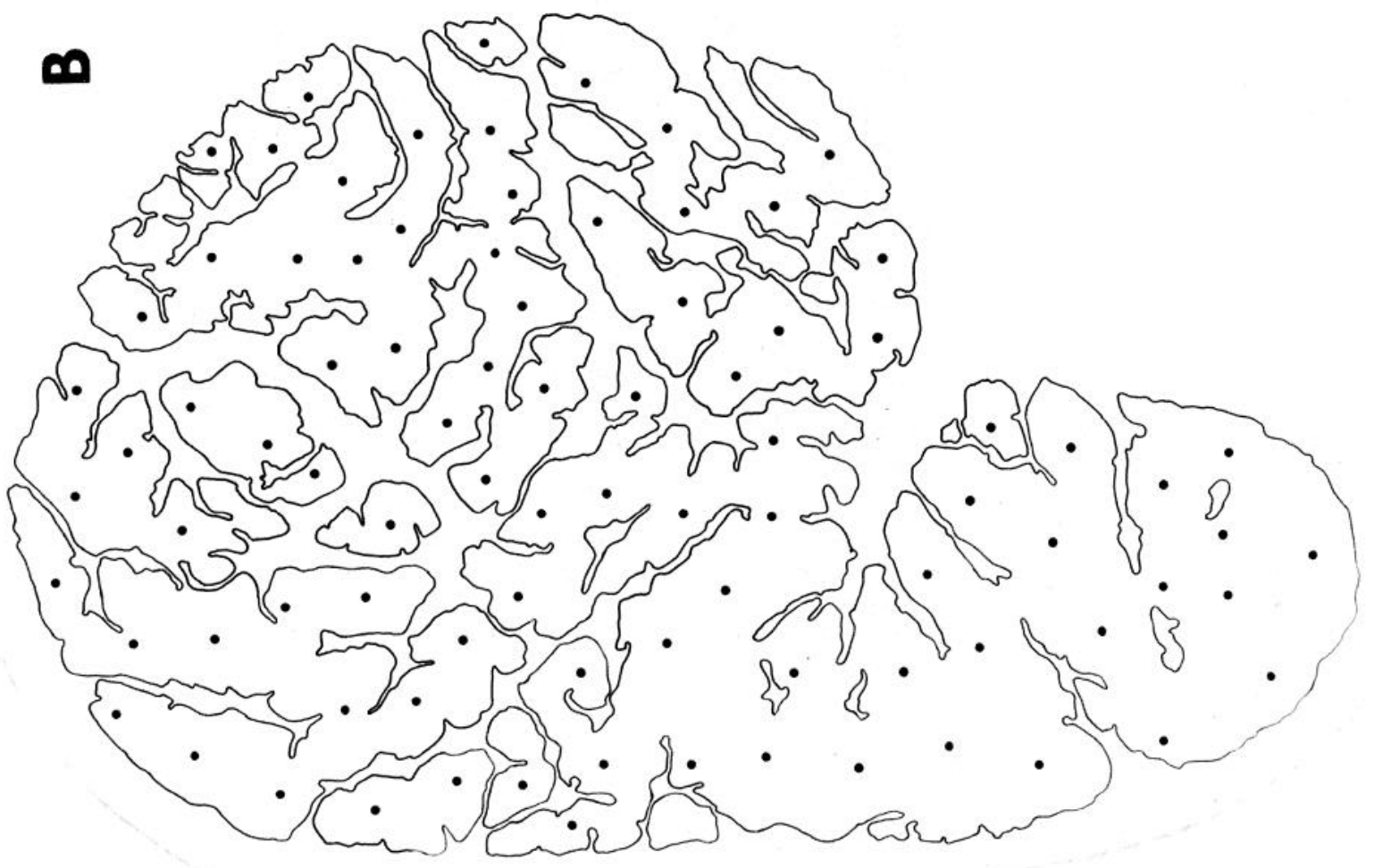

क्ष
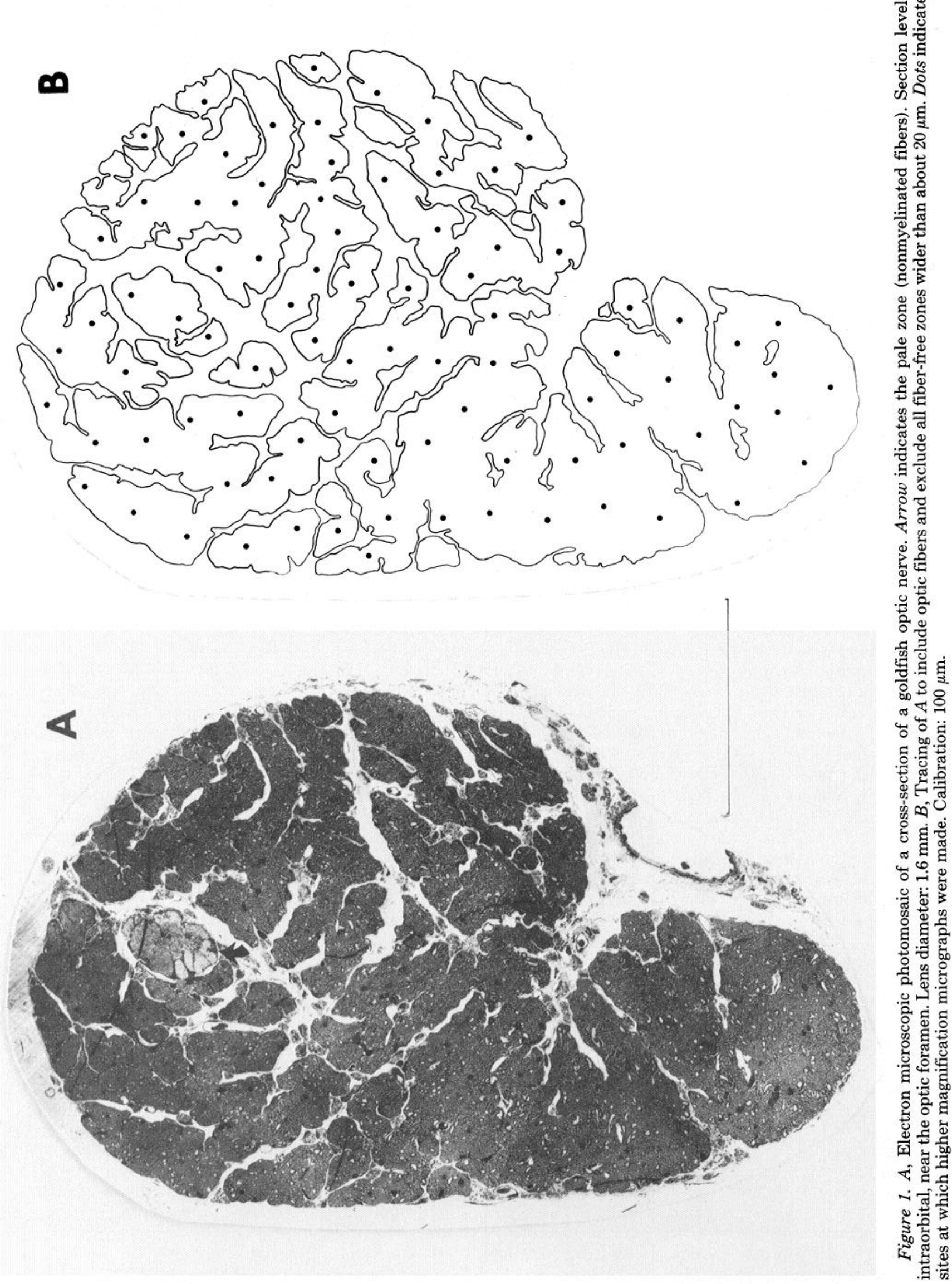
violet, dehydrated quickly in alcohol $(1 \mathrm{~min}, 95 \% ; 1 \mathrm{~min}$, $100 \%)$, cleared in xylene, and coverslipped under Permount. Whole-mounted retinas were processed in the same manner except that dehydration was longer. Alternate sections saved for resectioning were not counterstained but instead were postfixed in $2 \%$ phosphatebuffered $\mathrm{OsO}_{4}$, dehydrated, and embedded in Epon. Individual Epon-embedded sections then were cut out, mounted on a stem, and sectioned at $1 \mu \mathrm{m}$. These sections were stained in dilute toluidine blue $(0.1 \%)$ in $0.6 \%$ $\mathrm{Na}_{2} \mathrm{CO}_{3}$ at room temperature for 5 to $10 \mathrm{~min}$, rinsed in distilled water, and differentiated in $0.5 \%$ acetic acid. (Procedures normally used on $1-\mu \mathrm{m}$-thick Epon sections removed the HRP reaction product from the sections.)

Radioautography. Ten microCuries of tritiated proline (Neale et al., 1972) were injected into the eyes of selected experimental fish (described under "Results"). One day later, the fish were killed and the brains were fixed in Bouin's solution and embedded in paraffin. Each brain was sectioned serially in the transverse plane at $10 \mu \mathrm{m}$; sections were placed on slides and dewaxed, and the slides were dipped in Kodak NTB-3 emulsion. The emulsion was exposed for 6 weeks and developed in Kodak D19. Sections were stained through the emulsion with hematoxylin and eosin.

\section{Results}

Four groups of observations are presented below: (1) a description of the structure of the optic nerve and tract as seen in semithin sections, (2) a description of the nonmyelinated fibers and evidence that they are the new fibers, (3) an estimation of numbers of fibers in the optic nerve at various ages, and (4) several experimental results which demonstate patterns of order in the nerve.

General observations. Transverse sections of the optic nerve and tract at different points between the retina and brain had different characteristics (Fig. 2). Near the exit from the retina, fibers were small, generally lightly myelinated, and tightly packed into a relatively small cross-section (Fig. 2A). Although glial processes partitioned the nerve, there were no open spaces. On one edge, there was a strip (Fig. 2, $A$ and $B$ ) which stained less intensely than the rest of the nerve and which will be shown below to contain nonmyelinated fibers. Closer to the brain, the border of the nerve became increasingly indented; by midorbit, the entire cross-section was separated into bundles (Fig. $2 C$ ). The pale strip gradually fragmented into many fascicles, still relatively near one another but by no means contiguous and inside of the nerve, rather than on the edge, as before. Figure 3 illustrates the location and fragmentation of the pale fascicles in midorbital sections of six different nerves. At this level, the cross-section of the nerve was considerably larger than it was near the retina (compare Fig. 2, $A$ and $C$ ); this enlargement resulted partly from an increase in fiber diameters but mostly from the separation of bundles. More centrally, the bundles reunited and the nerve became more compact as it exited the orbit. From the midorbital region up to the chiasm (Fig. $2 D$ ), nearly all fibers were cut transversely, but central to the chiasm, this arrangement altered. Bundles of longitudinally sectioned fibers appeared (Fig. $2 E$ ); apparently, they had changed course to run perpendicularly to the long axis of the nerve. Their numbers increased progressively with more central sections, and for much of the postchiasmatic segment, including the brachia, the nerve appeared quite jumbled, with adjacent groups of fibers running at right angles to one another. Finally, the two brachia entered the rostral pole of the tectum, the dorsomedial brachium running along the boundary between tectum and torus longitudinalis and the ventrolateral brachium running along the boundary between tectum and tegmentum. The pale fascicles segregated approximately equally between the two brachia.

Several other structures warrant mention. The retinal vessels, most prominent inside and adjacent to the nerve near the eye, ran with the nerve throughout the orbit. Over this same segment, a suspensory ligament between orbital surface and sclera paralleled the nerve along its anterior border. Finally, a nerve of unknown origin, containing about 100 fibers, mostly myelinated, also accompanied the optic nerve. Near the eye, it penetrated the sclera and coursed between pigmented epithelium and sclera. Its termination was never established, but it was observed in the ventral part of the eye near the origin of the retractor lentis muscle and therefore may be identified tentatively as a motor nerve to that muscle of accommodation.

Nonmyelinated fibers. A distinctive pale zone was noted in toluidine blue-stained sections of the optic nerve from all fish with lens dianeters less than about $3 \mathrm{~mm}$ (that is, fish less than about 2 years old) and, occasionally, even from larger fish (Fig. $1 A$, arrow). The reason for the pallor was the absence of myelin as the electron micrograph in Figure $4 B$ shows. The pale fascicles were made up nearly entirely of nonmyelinated fibers, very much smaller and more densely packed than those elsewhere in the same section. Bundles near the pale zone had some, but fewer, nonmyelinated fibers, with the remainder lightly myelinated (Fig. $4 C$ ). Further away, the fibers were larger, nonmyelinated fibers were absent, and the myelin sheaths were the thickest (Fig. $4 D$ ). Figure $4 A$ shows the cross-sectional planimetric density and illustrates its systematic decrease with distance from the pale fascicle.

We expected that any new optic nerve fibers would be nonmyelinated since the myelination process comes after the outgrowth of the axon. If these nonmyelinated fibers were the new ones, then our observations were consistent with the suggestion (Rusoff and Easter, 1980) that fibers of similar age clustered together in the nerve. Moreover, the gradual change of the fiber population with distance from the pale fascicles suggested that the new fibers entered the nerve near those fibers born slightly earlier. Over time, the axons enlarged, became myelinated, and continued to grow and to be more heavily myelinated. As a result, fiber size, fraction of myelinated fibers, and thickness of the myelin sheath all increased with distance away from the pale fascicles. This interpretation rests on the belief that the nonmyelinated fibers were the new ones-not a functionally separate, permanently nonmyelinated population.

If the nonmyelinated fibers are the new ones, then lesions in peripheral retina ought to cause them and their 

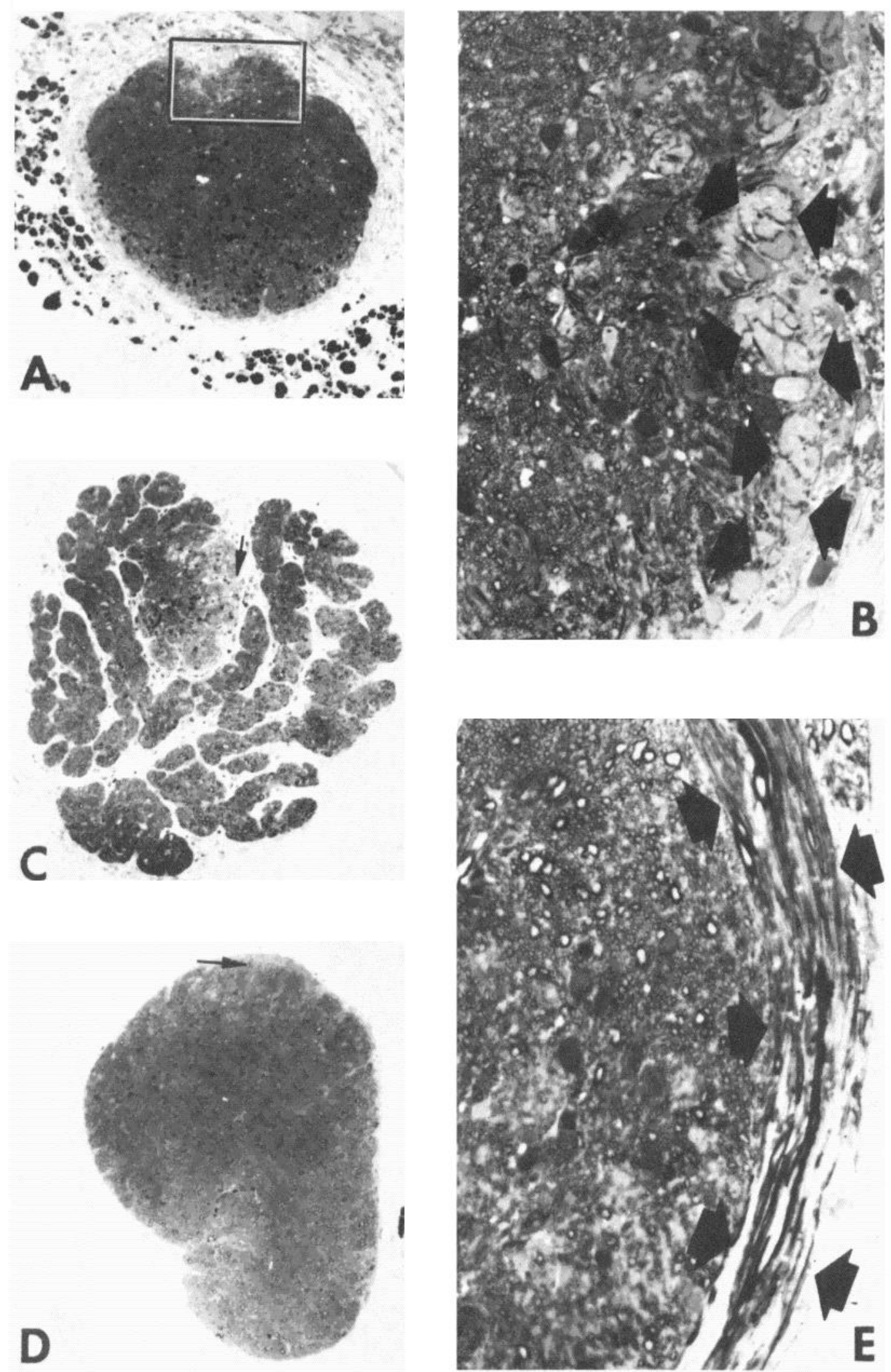

Figure 2. Light micrographs of 1- $\mu \mathrm{m}$-thick cross-sections through the optic nerve and tract. Lens diameter: $1.5 \mathrm{~mm}$. Calibration: $100 \mu \mathrm{m}$ for $A, C$, and $D ; 6 \mu \mathrm{m}$ for $B$ and $E$. $A$, Near the exit from the retina. The rectangle encloses the region shown in higher magnification in $B$. $B$, The arrows enclose a strip of pale fascicles. $C$, Midorbital section. Arrow indicates pale fascicles. $D$, Intracranial section at the level of the chiasm. Arrow indicates pale fascicles. $E$, Slightly closer to the brain than $D$. Arrows indicate a bundle of fibers running in the plane of the section perpendicular to the majority of fibers which are cut transversely. 

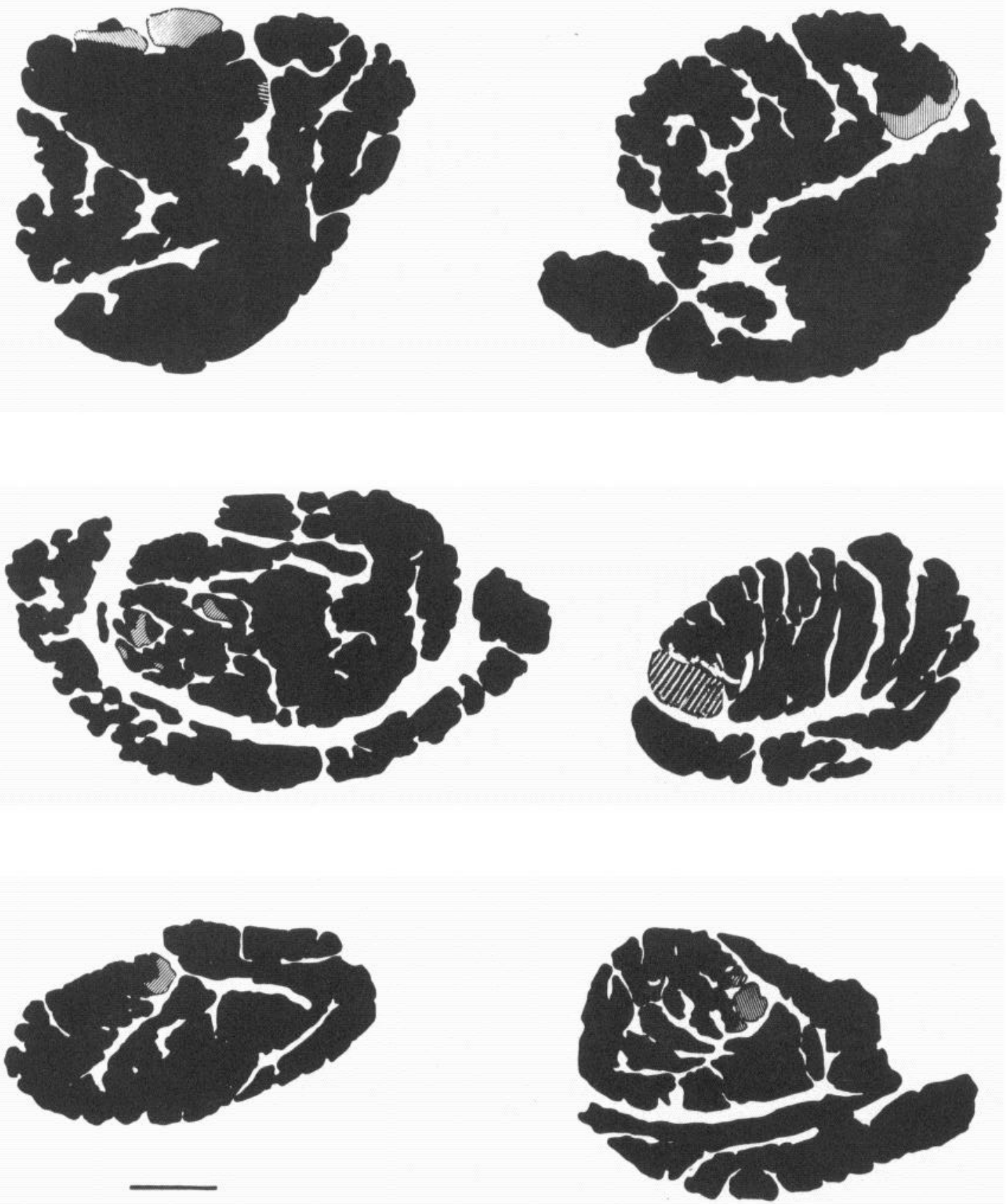

Figure 3. Camera lucida sketches of six transverse 1- $\mu$ m-thick sections of optic nerves of six different goldfish. The dark areas were occupied by myelinated fibers; the hatched areas were occupied by nonmyelinated fibers. Section levels: intraorbital. Orientations in dorsoventral and mediolateral axes are unspecified. Lens diameters: 1.5 to $2.5 \mathrm{~mm}$. Calibration: $100 \mu \mathrm{m}$.

neighbors to degenerate. Such lesions were made by slicing with a razor blade from the sclera through to the vitreous body, thus severing the axons of some peripheral ganglion cells. Ten small fish (lens diameters: 1.6 to 2.4 $\mathrm{mm})$ were used; two received lesions in dorsal, two in ventral, two in temporal, and two in nasal retina; two control fish received no lesion. Four days later, the fish were killed, and the retinas, nerves, and tecta were prepared for electron microscopy. The dimensions of the surgically isolated regions of retina were measured in semithin sections; they were typically about 1 to $2 \mathrm{~mm}$ in the circumferential direction and 100 to $200 \mu \mathrm{m}$ radially, occupying a small percentage of the retinal area. A crosssection of the intraorbital optic nerve of each fish was examined electron microscopically and scored for the presence and position of nonmyelinated fibers and degenerating myelinated fibers. The latter were distinguished by their dark cytoplasm and/or multiple myelin figures (Murray, 1976); because degenerating nonmyelinated axons could not be distinguished reliably, they were not scored.

The two control nerves were recognized easily by the 

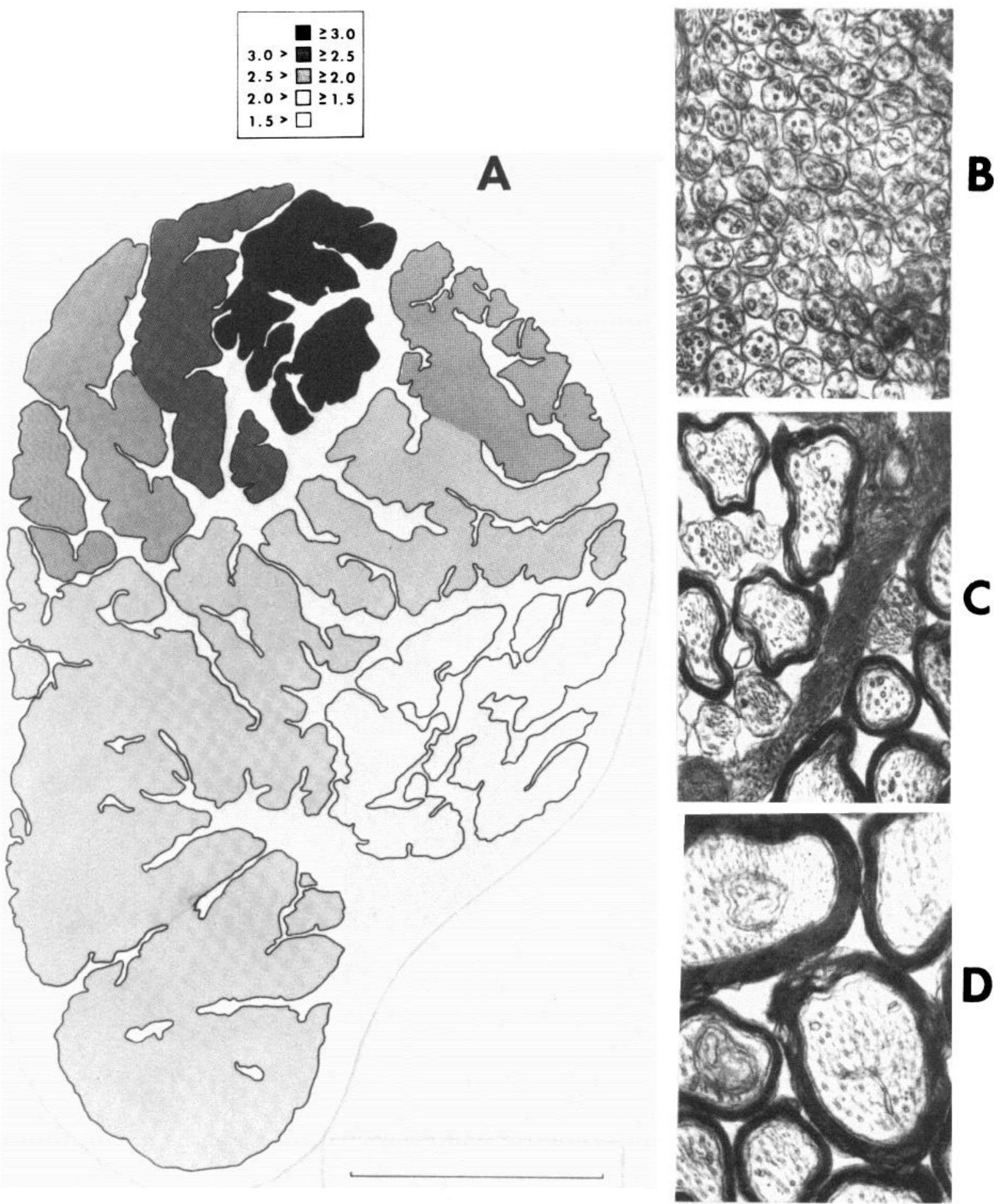

Figure 4. A, Tracing of an electron microscopic photomosaic of a transverse section of an optic nerve shaded (inset gives shading code) to indicate planimetric density (numbers of fibers per $\mu \mathrm{m}^{2}$ ). The same section as in Figure 1 is shown. $B, C$, and $D$, Electron micrographs from different zones of the nerve. $B$, In a pale fascicle, the region of highest planimetric density. $C$, Near the pale fascicles; intermediate planimetric density. $D$, Far from the pale fascicles; low planimetric density. Calibration: $100 \mu \mathrm{m}$ for $A$; $1.52 \mu \mathrm{m}$ for $B, C$, and $D$.

paucity of degenerating axons. One experimental nerve (nasal retinal lesion) also had practically no degenerating fibers, although the retina had a large lesion. This discrepancy remains unexplained. Two other experimental nerves (attached to a retina with a dorsal and one with a ventral lesion) had degenerating fibers spread diffusely over much of the nerve. The extent of the degeneration suggested inadvertent damage to the retinal blood supply. In the other five nerves, there was a single patch of degeneration near the nonmyelinated fibers, as illus- 
trated in Figure 5. This result is consistent with our suggestion that nonmyelinated fibers come from ganglion cells at the peripheral margin of the retina, that is, the new ganglion cells.

The rostral tectum, near the level of the brachial entry, also was examined electron microscopically in both nor$\mathrm{mal}$ and lesioned fish. Fibers from retinal ganglion cells enter the tectum near its rostral pole: those from ventral retina enter via the dorsomedial brachium of the optic tract and terminate in dorsal tectum, those from dorsal

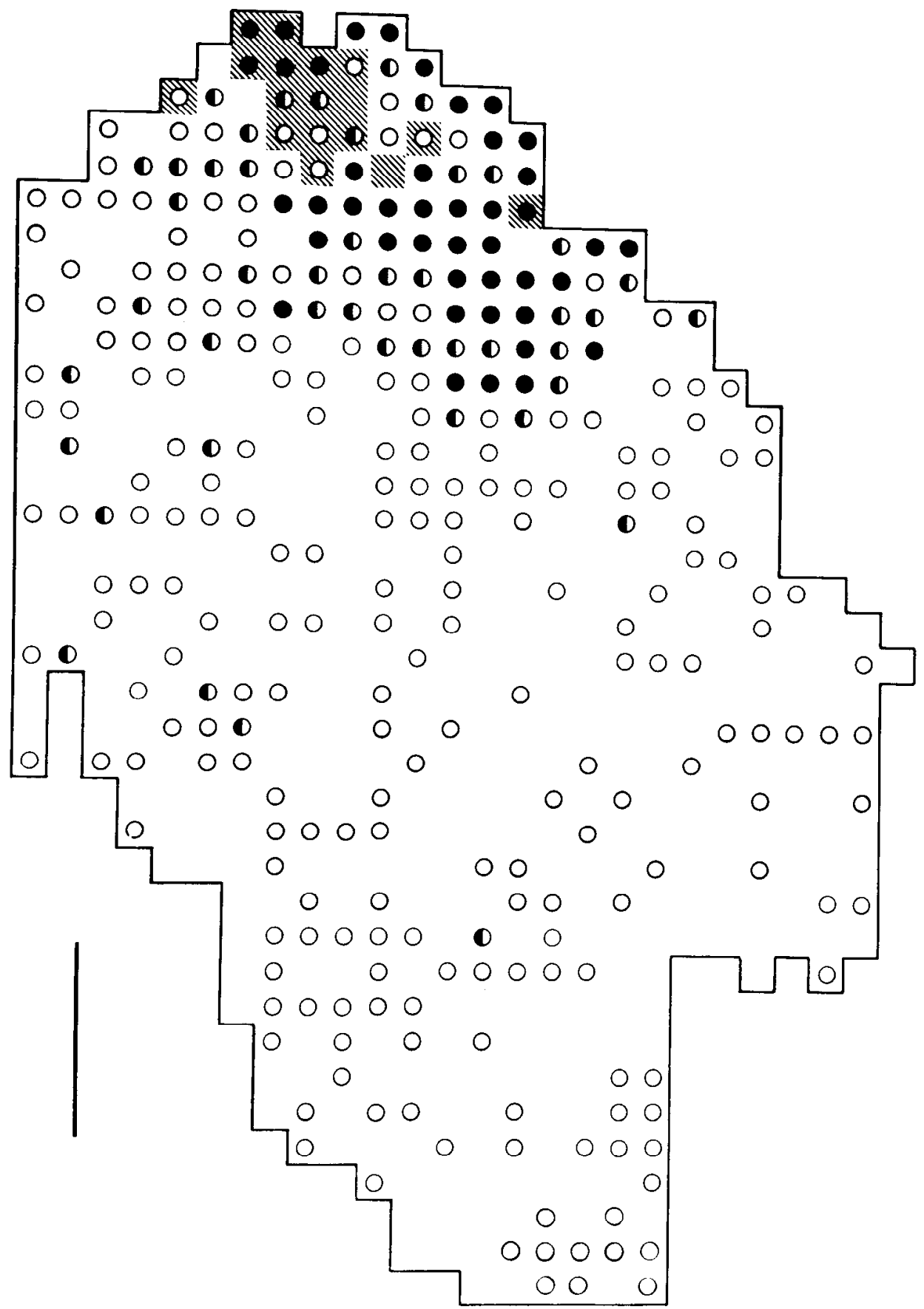

Figure 5. A scan of an intraorbital section of an optic nerve from a retina which had received a small peripheral lesion dorsally. The entire nerve was scanned stepwise, and each field of view (equivalent to a square) was scored for the presence of nonmyelinated fibers and degenerating myelinated fibers. Hatching indicates those areas which contained nonmyelinated fibers. The circles indicate those areas with degenerating fibers. 0,1 to 3 degenerating fibers; $\boldsymbol{O}, 4$ to 10 degenerating fibers; more than 10 degenerating fibers. Individual nerves varied greatly with respect to the mean level of degeneration. The numerous open circles in this example probably resulted from problems of fixation rather than degeneration caused by surgery. Other nerves were much cleaner, with very infrequent degenerating fibers over most of the cross-section. Calibration: $100 \mu \mathrm{m}$. 
retina enter via the ventrolateral brachium and terminate in ventral tectum, those from nasal retina enter via both brachia and terminate in caudal tectum, and those from temporal retina also enter via both brachia but terminate in rostral tectum. Those fibers from peripheral retinal cells terminate in the peripheral part of the appropriate region of tectum (Leghissa, 1955; Attardi and Sperry, 1963; Jacobson and Gaze, 1964; Schwassmann and Kruger, 1965). If the peripheral fibers course through peripheral tectum, near the torus longitudinalis dorsally and the midbrain tegmentum ventrally, then peripheral retinal lesions ought to produce fiber degeneration there. Moreover, if nonmyelinated fibers originate in peripheral retina, they should be found preferentially in peripheral tectum. Both of these predictions were upheld. Nonmyelinated fibers in the optic fiber layer were most numerous in peripheral tectum, particularly rostrally, as illustrated in Figure 6. Of the seven retinal lesions which produced degeneration in the optic nerve, all produced degeneration at the expected tectal sites. Specifically, peripheral ventral retinal lesions caused extensive degeneration in dorsomedial rostral tectum with no degenerated fibers in dorsolateral or ventral tectum. Dorsal retinal lesions gave the converse result. Nasal lesions resulted in degeneration on both dorsal and ventral hemitecta, again on the medial (peripheral) sides, as expected. The one effective temporal lesion gave degenerating fibers in dorsal, but not ventral, tectum. This asymmetry may reflect a poorly placed lesion which did not include both dorsal and ventral hemiretinas, but the important point here is that the degenerating fibers were on the medial side of tectum. These observations support the identification of the nonmyelinated fibers as the new ones.

Numbers of fibers. If the new cells added to the ganglion cell layer are truly ganglion cells, then there should be more optic fibers in the optic nerves of older fish. The numbers of nerve fibers were estimated in midorbital sections from 10 fish, from three size classes which corresponded to ages of about 1, 3, and 5 years (Johns and Easter, 1977) (Table I, column 1 and legend). The nerves of larger fish differed qualitatively from those of the smaller fish with respect to the presence of bundles of nonmyelinated fibers. While all four nerves from small fish had such bundles, only one nerve from a medium fish and none of the nerves from large ones had them (Table I, column 3). The optic nerves of larger fish were considerably larger than those of smaller ones, both in length and cross-section (Table I, column 2). Although fiber diameters were not measured systematically, it was clear that the larger nerves had larger fibers, confirming the findings of Marotte (1980). The mean planimetric density of fibers decreased with growth (Table I, columns 4 and 5). In spite of this, the numbers of fibers increased with age (Fig. 7, individual nerves; Table I, columns 6,7 , and 8 , mean values by group). If we assume that the small nerves were similar to earlier stages of the large ones, then about 40,000 fibers were added over years 2 and 3, and 20,000 fibers were added over years 4 and 5 . These increments correspond to rates of addition of about 54 and 27 fibers per day, respectively.

Order in the optic nerve. The previous sections support our suggestion (Rusoff and Easter, 1980) that the goldfish optic nerve is organized by age, that is, that axons from new ganglion cells enter the nerve together. In this section, we explore the question: To what extent do fibers which enter the nerve together remain together as they grow to the brain? The serial semithin sections seemed to suggest that fibers followed complicated paths through the nerve and tract. The only identified bundles, those of the nonmyelinated fibers, dispersed somewhat and did not remain in the same position throughout the course of the nerve (Figs. 2 and 3 ). However, the nonmyelinated fibers are numerous (thousands) and have a very distributed retinal origin (an entire annulus).

In an attempt to estimate the amount of interfiber dispersion, we traced and sketched, through a drawing tube, groups of HRP-filled fibers in the nerve and tract. Small groups of fibers were filled with HRP by inserting an insect pin coated with dried HRP into the peripheral retina. The enzyme was picked up by ganglion cells and axons of passage near the penetration site. The retinas, nerves, and tracts then were prepared for HRP visualization as usual. The retinas were whole mounted, and the nerves and tracts were sectioned longitudinally at $40 \mu \mathrm{m}$. In one typical case, a group of fibers was traced for over $800 \mu \mathrm{m}$ in the same section of the nerve. The distance between the most peripheral fibers in this group (not always the same pair) was $63 \pm 11 \mu \mathrm{m}$ (mean $\pm \mathrm{SD}$ ). The relative positions of individual fibers within the bundle also varied. For example, the distance between one pair varied from 0 to $33 \mu \mathrm{m}$ (mean separation, $14 \pm 10 \mu \mathrm{m}$ ). These observations show that individual fibers did not remain next to the same neighbors throughout the length of the optic nerve. The dispersion could have resulted from any or all of the following processes: adjacent bundles separating (compare Figs. 2 and 3 ), individual fibers crossing between bundles, and fibers dispersing within a bundle.

The reconstructed views using all of the sections of the nerve and tract from this fish also yielded information concerning the degree of retinotopic order within the nerve. Figure $8 A$ is a composite sketch which shows the filled axons in all of the sections superimposed in register as seen from above. The retinal whole mount showed that this injection had filled fibers from only about $1 \%$ of peripheral temporal retina, but the band of filled fibers extended across nearly half of the nerve. Figure $8 B$ is a side view of the nerve showing the position of filled fibers along the length of each section, and Figure $8 C$ shows reconstructed cross-sections of the nerve at three levels. The composite views of the optic tract (not shown) were similar. The filled fibers clearly deployed over much more than $1 \%$ of the cross-section of the nerve. We conclude that the nerve was somewhat ordered by retinal position since fibers which originated near one another on the retina were not spread randomly. However, the order was not very precise; fibers were clustered less tightly in the nerve than their parent cell bodies were in the retina.

The possible retinotopic order in the nerve was examined in another experiment which utilized the known retinal origins of fibers in the two brachia of the optic tract. We coated all of the fibers in one brachium with $\mathrm{HRP}$, allowed the HRP to be transported back to the 


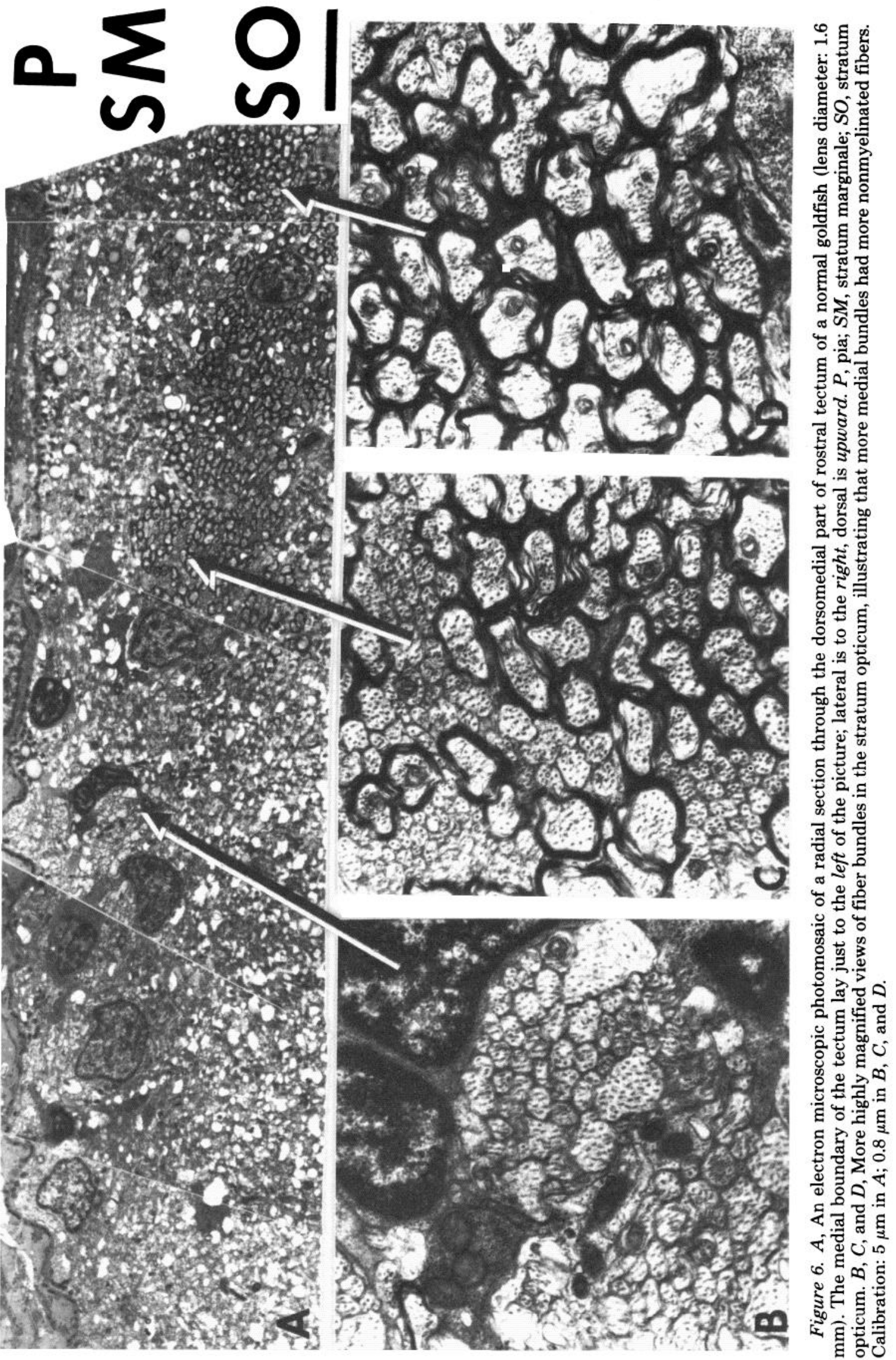


TABLE I

Numbers of nerve fibers estimated in midorbital sections

Measurements (means $\pm \mathrm{SD}$ ), given in order, of the three classes of fish (column 1), small $(N=4)$, medium $(N=3)$, and large $(N=3)$, include standard length: $3.4 \pm 0.4,7.8 \pm 0.7$, and $12.6 \pm 0.2 \mathrm{~cm}$; tip to tip length: $5.1 \pm 0.9,12.1 \pm 1.0$, and $19.5 \pm 1.4 \mathrm{~cm}$; weight: $1.2 \pm 0.4,16.7 \pm 3.0$, and $67.1 \pm 4.0 \mathrm{gm}$; and lens diameters: $1.6 \pm 0.2,2.8 \pm 0.2$, and $4.0 \pm 0.1 \mathrm{~mm}$. Nerve cross-section (columns 2 and 3 ) was measured in low magnification photomosaics and excludes fiber-free areas wider than approximately $20 \mu \mathrm{m}$. Planimetric density (columns 4 and 5 ) is expressed as numbers of fibers per $\mu \mathrm{m}^{2}$; values are the extremes found in individual high magnification electron micrographs.

\begin{tabular}{|c|c|c|c|c|c|c|c|}
\hline 1 & 2 & 3 & 4 & 5 & 6 & 7 & 8 \\
\hline \multirow{2}{*}{$\begin{array}{l}\text { Size of } \\
\text { Fish }\end{array}$} & \multicolumn{2}{|c|}{$\begin{array}{l}\text { Nerve Cross-section } \\
\text { (Mean) }\end{array}$} & \multicolumn{2}{|c|}{$\begin{array}{l}\text { Planimetric Density } \\
\text { (Range) }\end{array}$} & \multicolumn{3}{|c|}{$\begin{array}{c}\text { Estimated Number of Fibers per Nerve } \\
\text { (Mean) }\end{array}$} \\
\hline & Total & $\begin{array}{l}\text { Nonmyelinated } \\
\text { Fibers }\end{array}$ & Myelinated Fibers & $\begin{array}{c}\text { Nonmyelinated } \\
\text { Fibers }\end{array}$ & Myelinated Fibers & $\begin{array}{l}\text { Nonmyelinated } \\
\text { Fibers }\end{array}$ & Total \\
\hline & \multicolumn{2}{|c|}{$\mu m^{2}$} & \multicolumn{2}{|c|}{$\mu m^{-2}$} & & & \\
\hline Small & 56,781 & 230 & $0.72-4.01$ & $5.9-29.1$ & 115,438 & 4,080 & 119,518 \\
\hline Medium & 267,452 & 126 & $0.26-1.09$ & $8.1-13.3$ & 161,577 & 1,247 & 162,824 \\
\hline
\end{tabular}

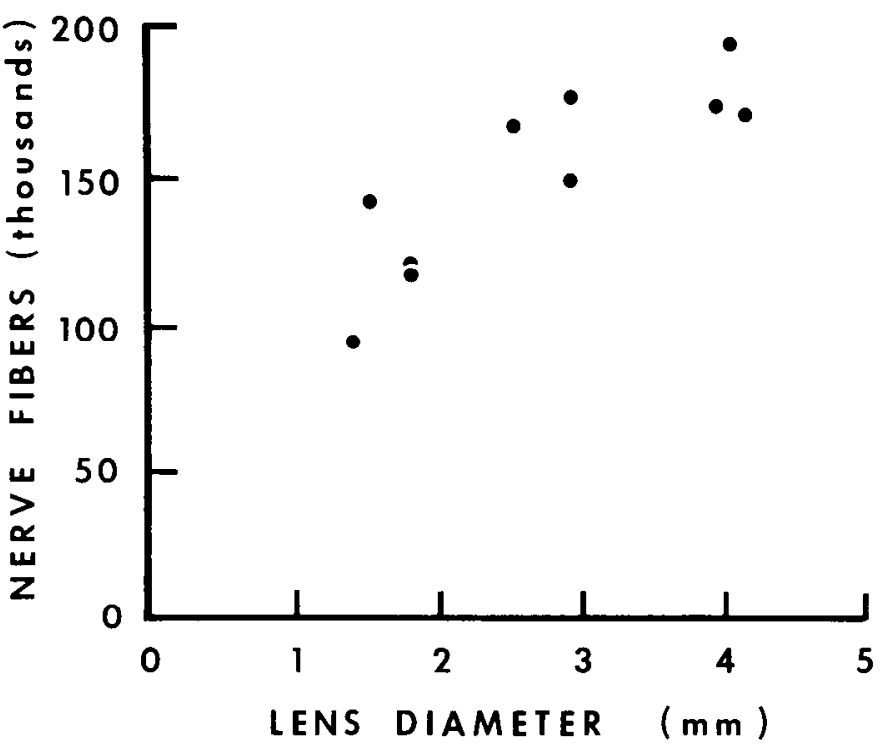

Figure 7. Numbers of nerve fibers, both myelinated and nonmyelinated, in the optic nerves of 10 goldfish of various sizes indicated by lens diameters. See text and Table I for details.

retina retrogradely, and then determined the distribution of filled fibers at different points in the nerve. Since fibers in the ventrolateral and dorsomedial brachia originate from cells in the dorsal and ventral hemiretinas, respectively (Leghissa, 1955; Attardi and Sperry, 1963), this procedure allowed us to determine the segregation at various points in the nerve between fibers from dorsal and ventral retinal ganglion cells. A total of 41 brachia were cut and coated with Gelfoam (Upjohn) soaked in HRP. Then the retinas, nerves, and tracts were prepared as described under "Materials and Methods" to demonstrate the distribution of HRP reaction product. The retinas were prepared as whole mounts and the distribution of filled ganglion cells on them was used to screen for unsuccessful brachial cuts. Twenty-six experiments were rejected because either no retinal ganglion cells were filled (15 cases) or the filled ganglion cells were not restricted to one hemiretina (11 cases). In the other 15 cases, the ganglion cells in the appropriate hemiretina were filled with HRP reaction product. A few filled ganglion cells were always seen in the "wrong" hemi- retina, especially near the dorsal/ventral retinal boundary (Fig. 9). The fibers of these cells may have been in the "wrong" brachium. Alternatively, they may have been in the "correct" brachium but were damaged inadvertently and filled. Transverse sections through the nerves and tracts in each of these successful cases showed a striking segregation of fibers from the two hemiretinas, especially near the eye. Figure 10 shows sections from two nerves, one with the fibers from ventral retina filled with HRP (Fig. 10, $A, B$, and $C$ ) and the other with fibers filled from dorsal retina (Fig. 10, $D, E$, and $F$ ). The two nerves present complementary images. Near the exit from the eye, fibers from dorsal retina occupied a trapezoidal zone in the center of the nerve (Fig. 10D) and axons from ventral retina occupied two flanking zones (Fig. 10A). The strip of nonmyelinated axons (Fig. 2, $A$ and $B$ ) was located on semithin sections adjacent to the thick ones shown here. It extended across the narrow end of each nerve at the point of convergence of the bands of fibers from dorsal and ventral retinas (Fig. 10, $A$ and $D$,arrows). The addition of the nonmyelinated fibers at one edge suggests that there is a gradient of age across the nerve with oldest axons (from central retina) at the opposite edge of the nerve. This pattern is similar to that in the ribbon-shaped nerves of cichlid fish (Scholes, 1979) and to the model for organization of the goldfish optic nerve proposed by Dawnay (1979b). More centrally, where the nerve was divided into many small bundles (Fig. $2 \mathrm{C}$ ), the boundaries in the nerve became hazier with filled and unfilled axons interspersed. However, the bulk of the fibers from dorsal retina remained internal to fibers from ventral retinal cells (Fig. 10, $B$ and $E)$. This basic pattern was maintained past the chiasm although the mixing continued to increase more centrally. Central to the chiasm (not shown), groups of filled fibers ran perpendicularly to the long axis of the tract as ventral retinal fibers passed through the domain of those from dorsal retina to reach the correct brachium. This re-sorting presumably accounted for the tangentially cut axons noted in the semithin sections (Fig. $2 E$ ). Close to the bifurcation of the optic tract, all of the axons from ventral retina were together and segregated from those of dorsal cells (Fig. 10, $C$ and $F$ ).

The final approach to elucidating the order in the nerve was to section some of the fibers in the orbit and 


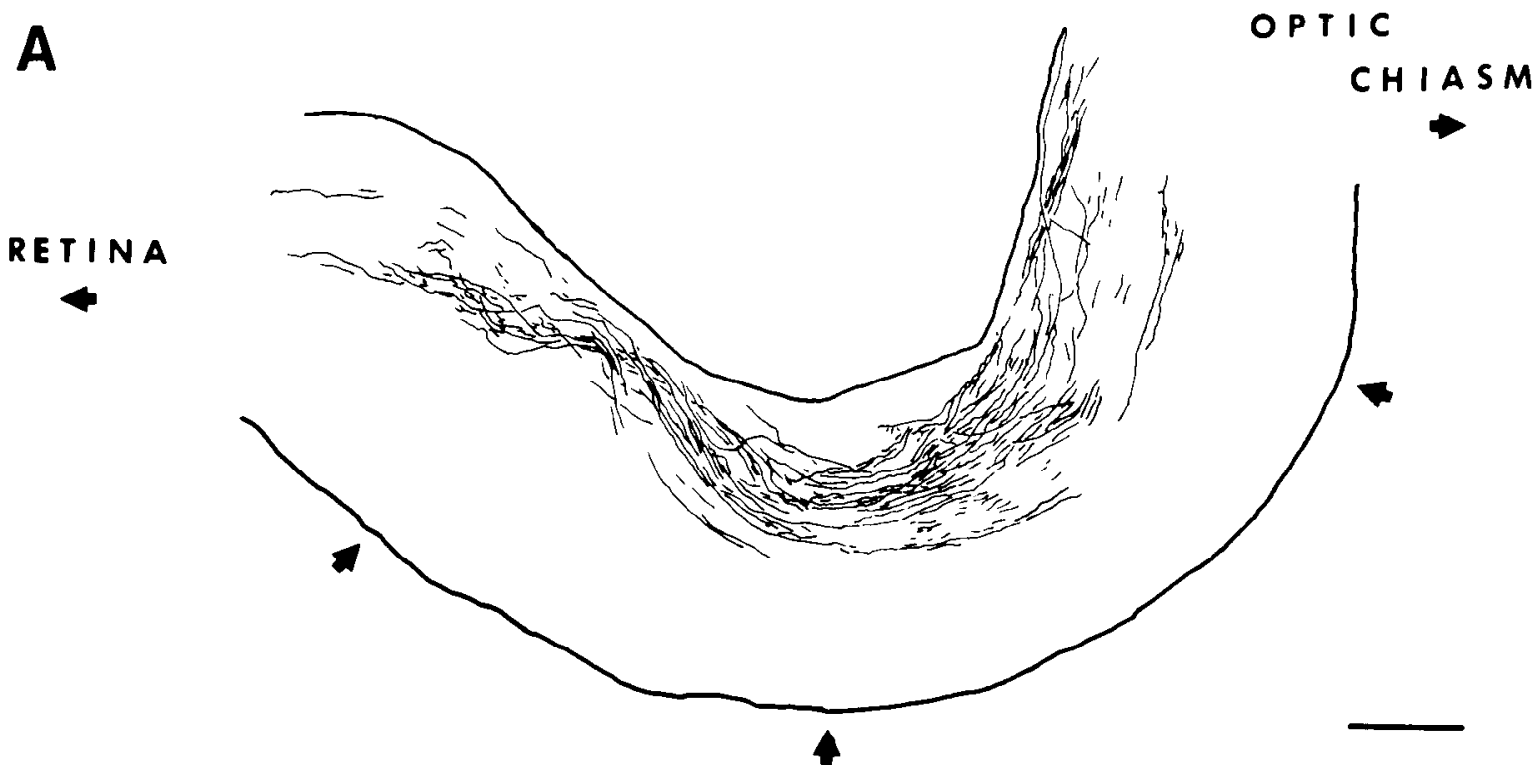

B
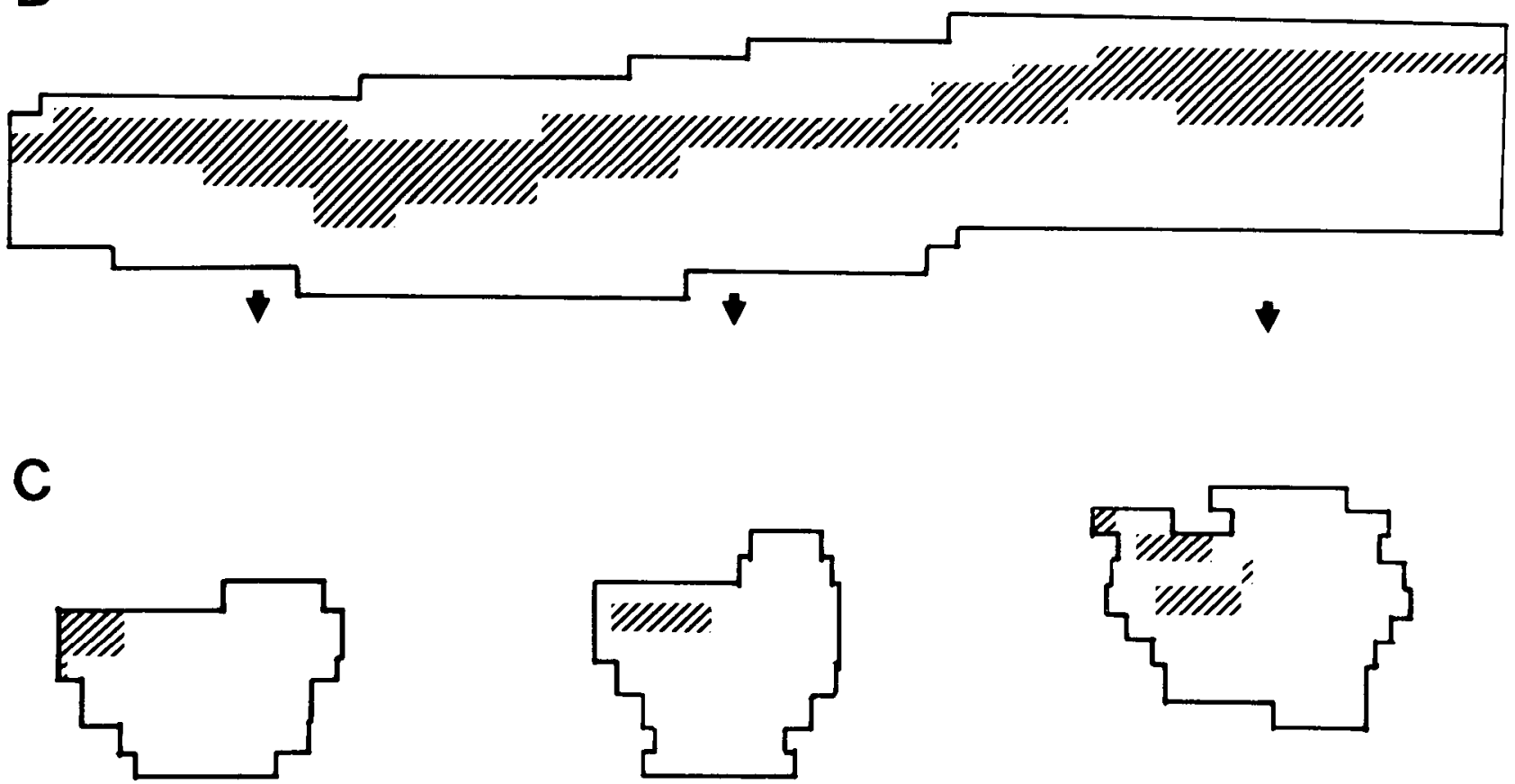

Figure 8. Three views of the fibers labeled by a small intraretinal injection of HRP. $A$, View from above showing, in superposition, camera lucida sketches of all sections of the nerve to reveal the labeled fibers (thin tracings) within the nerve (thick outer lines). $B$, A side view of the same sections which contributed to $A$. Here, the portions of individual sections which contained labeled fibers are indicated by hatching. $C$, A third view of these same sections showing the reconstructed transverse sections at the three positions shown by the arrows in $A$ and $B$. Calibration: $100 \mu \mathrm{m}$.

then visualize the tectal scotoma. The retina projects topographically onto the tectum (Jacobson and Gaze, 1964; Schwassmann and Kruger, 1965). If the fibers in the fish's nerve are segregated according to their retinal positions of origin, then partial section of the nerve should produce a tectal zone of denervation corresponding to the retinal origin. We tested this prediction anatomically by hemisecting the right optic nerves of five animals (lens diameters, 2.0 to $2.6 \mathrm{~mm}$ ) and then deter- mining the retinotectal projection radioautographically. The dorsal surface of the nerve was exposed, and a small incision, about $1 \mathrm{~mm}$ long, was made through the middle of the sheath, parallel to the long axis of the nerve. Then, one blade of a pair of iris scissors penetrated the incision and the anteromedial half of the nerve was severed. Four days later, both eyes were injected with tritiated proline, and the animals were killed 1 day after that. Semithin sections of the experimental nerves, just central to the 


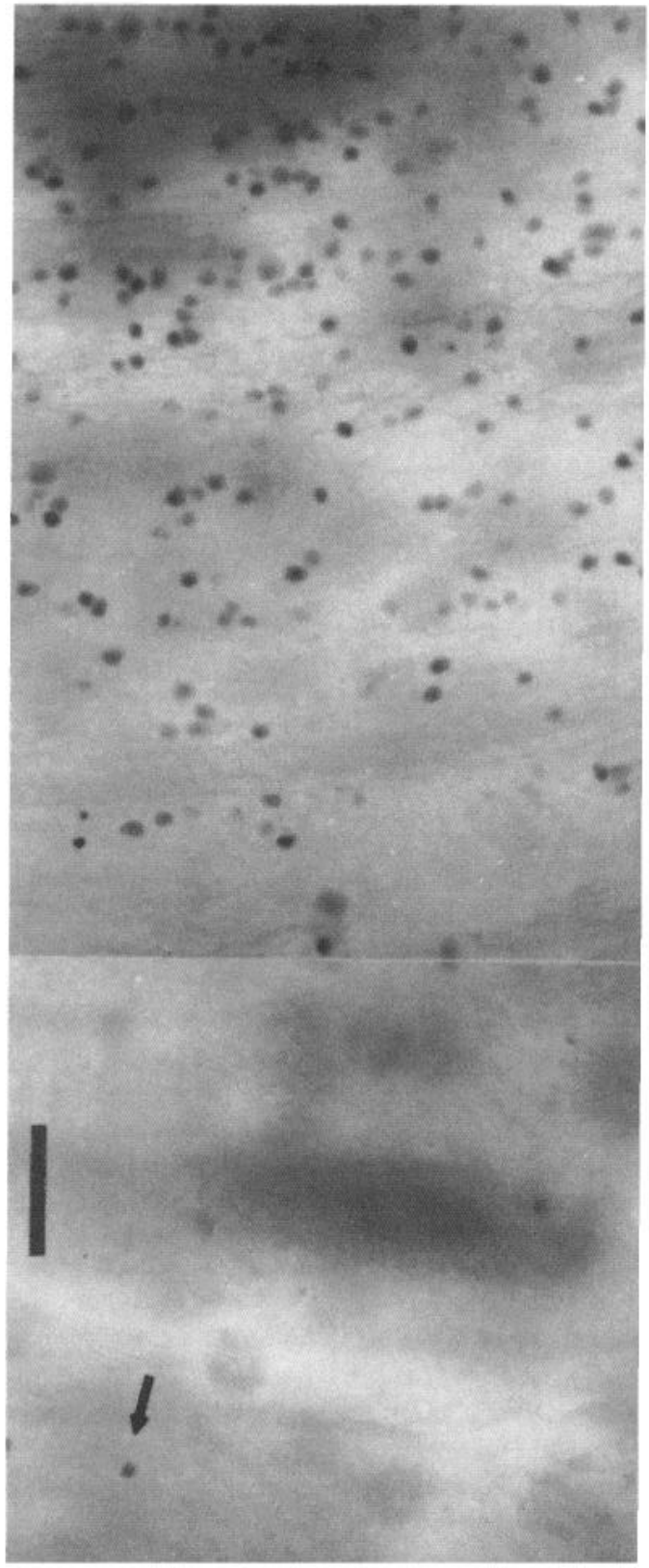

Figure 9. A portion of the whole-mounted retina showing the boundary between ganglion cells filled with HRP reaction product (dorsal) and unfilled cells (ventral) after filling the ventrolateral brachium with HRP. Although the boundary is relatively distinct, a few filled ganglion cells are found in ventral retina (arrow), especially near the boundary. Calibration: 50 $\mu \mathrm{m}$.

lesion, were examined light microscopically. The degenerated fibers were evident by their darker and disorganized myelin. The percentage of the total cross-section of the nerve occupied by degenerating fibers was measured on the digitizer. The brains were examined in radioautographs of transverse sections.

In all cases, the partial sections were successful; the degenerated portion of the nerve made up 35 to $65 \%$ of the total cross-section. All control tecta were labeled normally, but the experimental tecta were not. One ex- perimental tectum showed a wedge of unlabeled tissue, narrow rostrally, wide caudally, but the other four showed annular unlabeled zones. The example illustrated in Figure 11 shows labeled peripheral and central tectum and an intermediate unlabeled annulus. One other tectum showed a similar pattern. The other two showed only two zones, a central labeled one and a peripheral, unlabeled one. These patterns will be discussed in the next section.

\section{Discussion}

Order in the nerve and its origin. The foregoing results support the idea that new fibers are added to the optic nerve of goldfish for several years and that the addition is orderly. Born at the annular margin of the retina, the fibers grow alongside axons from the same retinal sector toward the optic papilla. Once there, they appear to follow the central retinal artery as it exits from the papilla (Bunt, 1980). Past the papilla, the artery leaves the nerve, and the new fibers follow the artery to the edge of the nerve, forming a new edge to which subsequent axons will be added in a similar fashion. The ordering by sector is maintained as the axons from one retinal sector are always found in the slab at a position adjacent to other fibers already in place from a more central position in the same sector. This process is essentially a continuation of the earliest outgrowth of retinal axons which has been described in another cyprinid, the zebra fish (Bodick and Levinthal, 1980).

In several respects, our interpretation resembles the "chronotopic" model of organization of the goldfish optic nerve which was outlined by Dawnay (1979b). The main difference between the two is in the disposition of the dorsal retinal fibers. According to our view (see Fig. 10, $A$ and $D$ ), they extend through the entire cross-section, while in Dawnay's model, they are surrounded on three sides by fibers from ventral hemiretina and do not extend to the dorsal boundary of the papilla.

Our scheme also resembles the organization of the ribbon-shaped nerve of cichlids (Scholes, 1979) and perhaps of perciform fish generally. The analogy to a polar coordinate system is evident. In both cases, distance from the disc, $r$, is mapped in one direction, and the position by sector, $\theta$, is mapped in the other. In both cases, the retinal annulus probably has been opened at the embryonic fissure in order to create a slab of fibers with those from either side of the fissure at opposite ends of the slab. Thus, if the right retina was marked like a clock face with the embryonic fissure on the radius at 6 o'clock, axons in each new slab in the nerve would be ordered linearly, from caudal to rostral, by retinal positions 6-912-3-6 o'clock, as shown in Figure 12. Sector $(\theta)$ maps along the lines parallel to the base of the trapezoid; distance from the disc $(r)$ maps perpendicularly. There are two differences between the nerves of goldfish and cichlids. The first is in the shape of the nerve as it exits the retina: the compact trapezoid versus the elongated ribbon. In the trapezoid, the narrower base is narrower because it accommodates smaller fibers, the new ones. However, the height and width of the trapezoid are quite similar; that is, both coordinates, $r$ and $\theta$, are compressed into about the same distance. In contrast, the cichlid's 

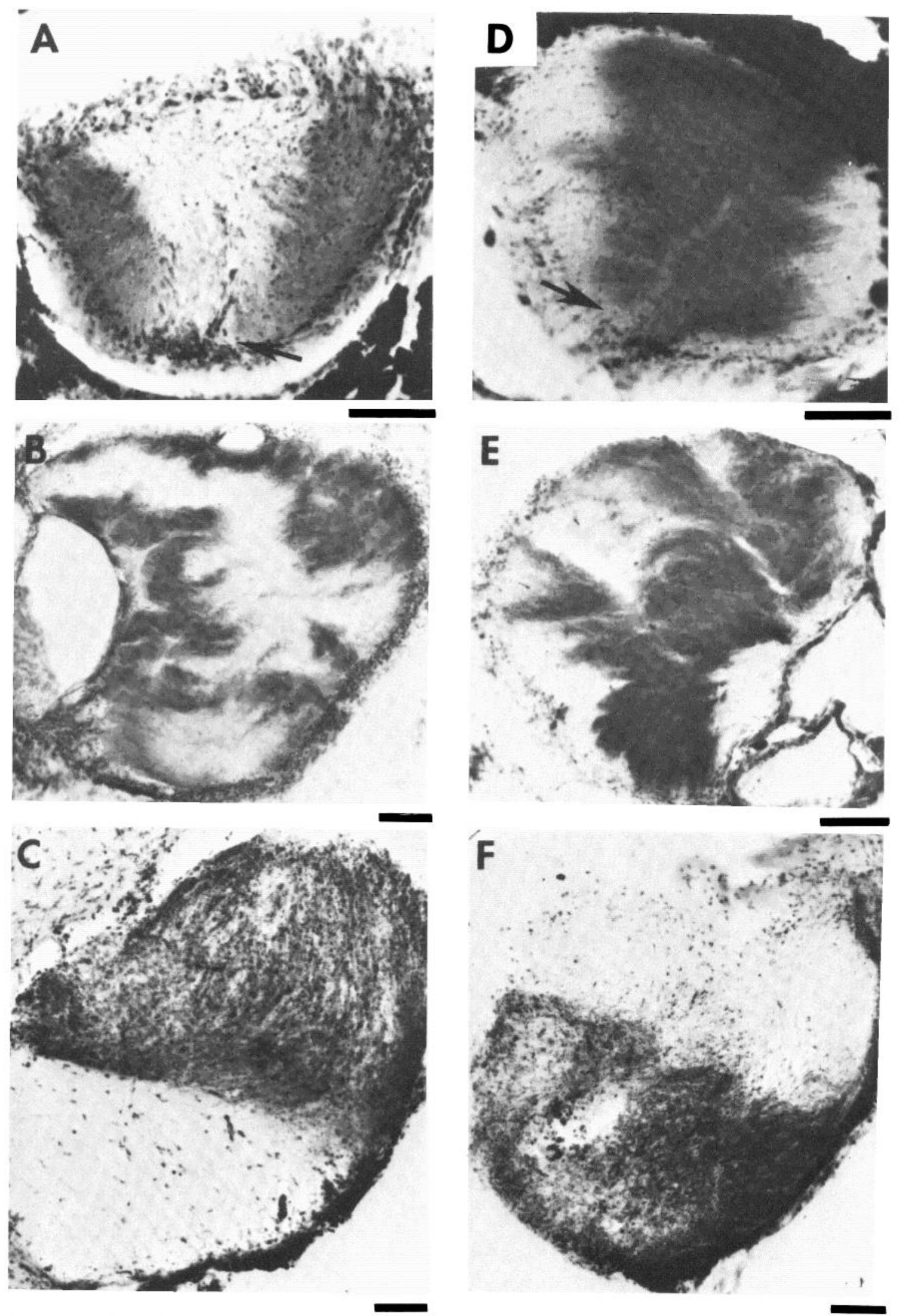

Figure 10. Cross-sections (frozen, $40 \mu \mathrm{m}$ thick) of two optic pathways (right nerve and left tract) showing areas filled with HRP reaction product after filling one brachium with HRP. Left side of figure, Dorsomedial brachium (carrying axons from ventral retina) was filled. Distance from the retina: $A, 40 ; B, 360 ; C, 2,000 \mu \mathrm{m}$. Right side of figure, Ventrolateral brachium (carrying axons from dorsal retina) was filled. Data are from the same animal as in Figure 9. Distance from the retina: $D, 80 ; E, 450 ; F, 1,800$ $\mu \mathrm{m}$. Ventral is down; the right side of the animals is to the left. Arrows show location of nonmyelinated fibers. Calibrations (bar below each panel): $100 \mu \mathrm{m}$. 


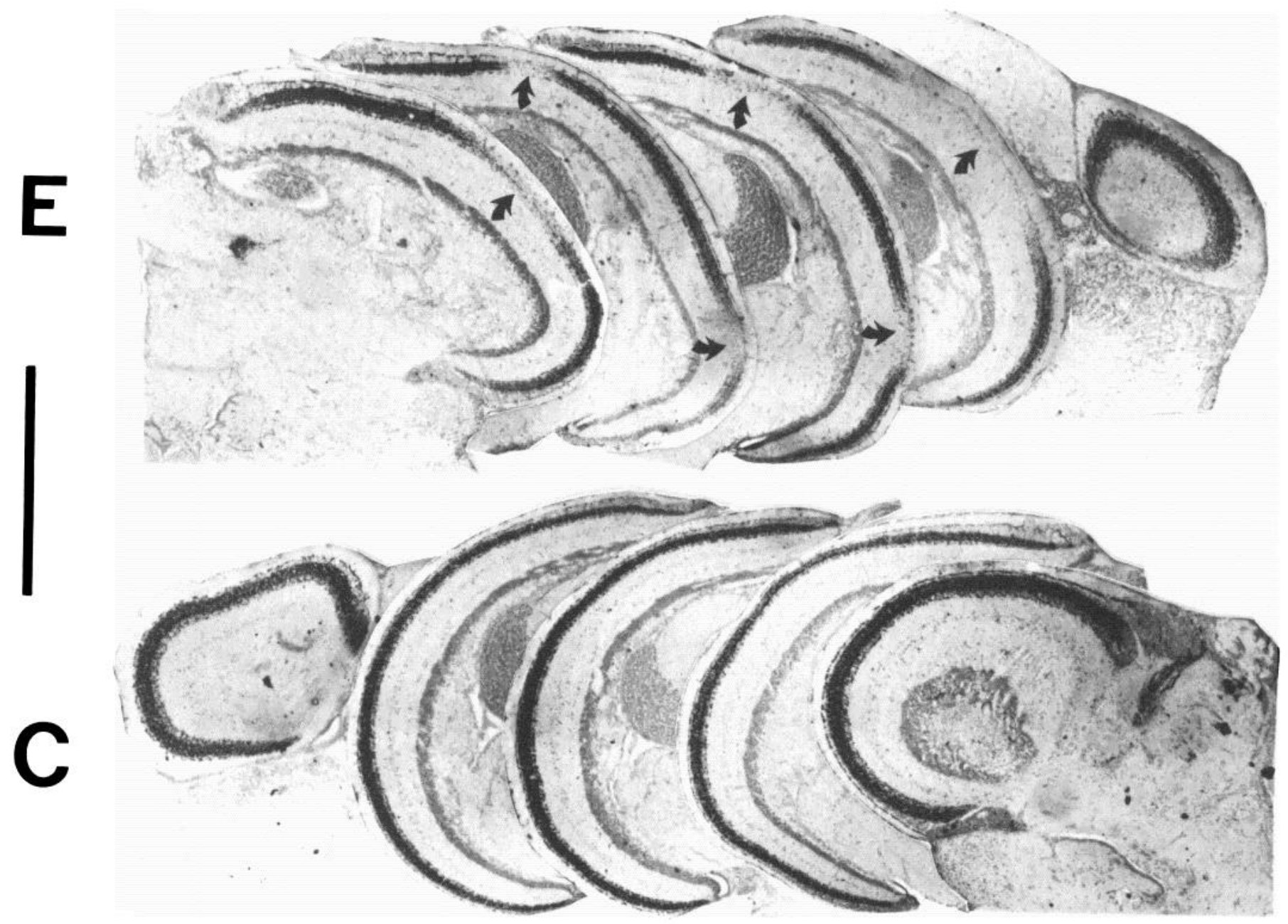

Figure 11. Radioautograms from both tectal lobes of an animal in which the right optic nerve had been hemisected 5 days before sacrifice and in which tritiated proline had been injected into both eyes 1 day before sacrifice. Adjacent sections in the illustration were separated by approximately $600 \mu \mathrm{m}$ in the animal. $E$, Experimental (left) tectum. Arrows indicate zones of low grain density which cover an annular portion of the tectal surface. Within sections: dorsal, upward; medial, left. Rostral sections are to the left. $C$, Control (right) tectum. Note that there are no zones of low grain density in the region of optic fiber input. Within sections: dorsal, upward; medial, right. Rostral sections are to the right. Calibration: $1 \mathrm{~mm}$.

elongated papilla gives much more space to $r$ than to $\theta$. The second difference lies in the organization of the nerve after it leaves the retina. In the cichlids, the ribbonlike shape of the nerve and its internal organization are maintained until very near its entry into the brain. In contrast, the goldfish optic nerve soon becomes fasciculated, and the original order becomes somewhat scrambled. This impression was derived from several observations. The brachial filling experiments revealed considerable intermingling of fibers from the two hemiretinas (Fig. 10). The intraretinal filling of neighboring ganglion cells showed that their fibers were relatively less circumscribed in the cross-section of the nerve than were their somata in the retina (Fig. 8). Presumably, when the axons lost their close relationships to one another, they gained new neighbors from elsewhere in the retina. This same impression was gained from tracking the nonmyelinated fibers. Although they left the retina together in a strip, they were soon segregated into separate fascicles which were often quite dispersed (Fig. 3). Finally, the hemisec- tion of the nerve and the subsequent appearance of an annular scotoma in the tectum demonstrated that the retinal annular origins of the fascicles were maintained (Fig. 11). Moreover, bundles of fibers of similar ages (and arising from adjacent annuli) must have been near one another. Otherwise, the hemisection would have produced noncontiguous unlabeled annuli. This inference is consistent with the impression gained by electron microscopy-fascicles resembled their neighbors more than distant fascicles.

This experiment also demonstrated another aspect of the postretinal scrambling. In all cases, the anteromedial half of the nerve was cut; if the retinal position mapped predictably onto the cross-section of the orbital portion of the nerve, then it would be expected that the tectal scotoma would always appear in the same location, but it did not. In two cases, the input from central retina was intact, and that of peripheral retina had been interrupted. This would be expected if the nonmyelinated fibers and nearby fascicles had been in the anteromedial half of the 


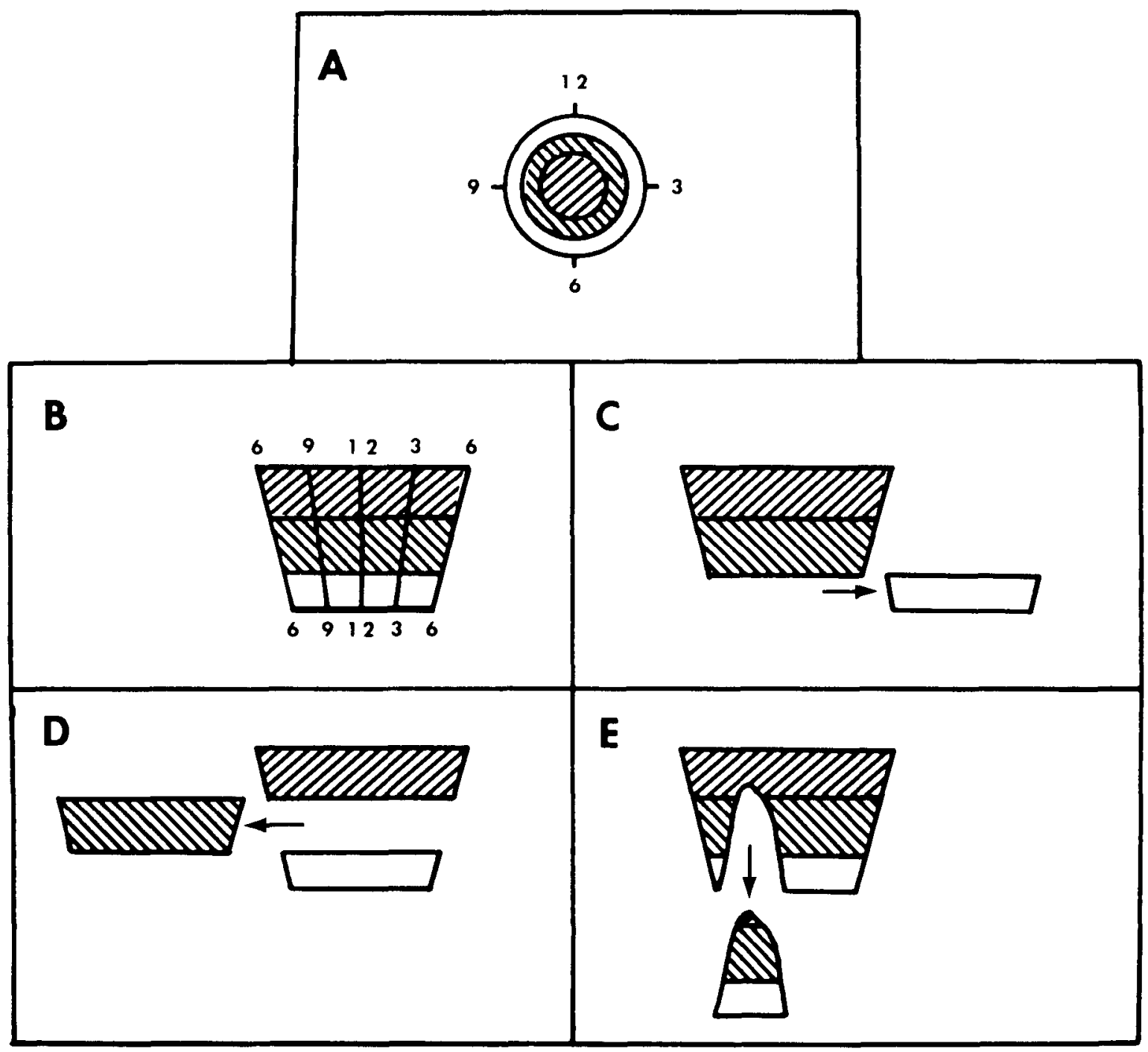

Figure 12. Schematic views of the retina $(A)$ and optic nerve in cross-section $(B, C, D$, and $E$ ) (not to scale). $A$, A view of the surface of the retina, divided into three annuli, coded by diagonal lines or their absence. The numbers give the clock face positions which indicate the variable, $\theta$. The distance from the center gives the other variable, $r$. $B$, The normal disposition of optic fibers just behind the eye. The diagonal lines and numbers indicate the retinal origins of the fibers as in $A$. Note that $r$ and $\theta$ map orthogonally. $C$. Section of the fibers nearest the narrow base of the trapezoid would axotomize ganglion cells from the most peripheral retina and denervate the most peripheral annulus in the tectum. $D$, Section of fibers in the center of the trapezoid would axotomize ganglion cells of the intermediate retinal annulus and denervate an intermediate tectal annulus (as in Fig. 11). $E$, The deleted region shows the population of fibers which would have been sectioned to produce the wedge-shaped denervated zone in the tectum which was mentioned in the text. The lesions schematized in $D$ and $E$ could not have been made, using the method described in the text, if the fibers maintained the same order as in $B$.

nerve. The surgery would have clipped the narrow base off of the aforementioned trapezoid (Fig. 12C). In two other cases, however, the peripheral and central retinal inputs were intact, and an intermediate zone had been isolated. This result implies that the nonmyelinated fibers were in the posterolateral half of the nerve. Moreover, the scotoma could have occurred only if the lesion interrupted fibers in a band between the bases of the trapezoid (Fig. 12D). Such an internal deletion would not have been possible if the original order were maintained, since the hemisection included one superficial half of the nerve (confirmed by histology). Moreover, the wedgeshaped scotoma found in one animal is not consistent with a simple deletion of a part of the nerve organized as these were at the level of the papilla (Fig. 12E). There- fore, the fascicles of fibers associated at the optic papilla are not rigidly locked into place in the nerve but may move about as they cross the orbit in such a way that the map of the retinal surface onto the cross-section of the nerve is twisted and distorted.

There are two earlier reports which suggested a different organization in the optic nerve of fish. In the first of these, Jacobson and Gaze (1965) hemisected the goldfish optic nerve near the eye and then plotted the electrophysiological visuotectal map. They found that section of the anteromedial or posterolateral half of the nerve produced a scotoma over the caudal or rostral half, respectively, of the contralateral tectum. For such a result to be consistent with the conclusions of this paper, the nerves must have been cut accurately down the 
middle of the trapezoid at the 12 o'clock position (Fig. $12 B$ ) so that one ventral quadrant and the adjacent dorsal quadrant of the retina were axotomized. Our hemisections reported above yielded very different scotomata. Wherein lay the source of the difference between these two results? We believe that two factors were probably involved. Jacobson and Gaze probably cut nearer the eye than we did, at the level where the nerve is most ordered as in Figure 10, $A$ and $D$. Also, if there had been some annular organization to the scotomata that they produced, it could easily have been missed with the electrophysiological technique, since it samples only a part of the retinotectal projection. When the eye is in air, as it was in their experiments, the most peripheral regions of the retina cannot be stimulated visually, owing to corneal refraction (Meyer, 1977; Schmidt et al., 1978). In addition, only the dorsal half of the tectum can be probed by the microelectrode. Therefore, somewhat less than half of the retinotectal projection is sampled electrophysiologically, and if there were annular scotomata in unsampled regions, they would go undetected. The radioautographic technique which we used, on the other hand, samples the entire projection, as demonstrated by the complete tectal labeling on the control side shown in Figure 11.

The second discrepant report (Schwassmann, 1975) concerned the visual system of a holocentrid, Myripristis teiognathos. The optic nerves of this animal are divided at the chiasm into seven to nine interdigitating fascicles. Schwassmann sectioned individual fascicles and found that they projected to rostrocaudal strips of tectum. Such a pattern is not readily related to any age-dependent segregation of retinal fibers. In fact, it is reminiscent of the pattern seen in the optic nerve from the lateral eye of the horseshoe crab, Limulus polyphemus (Snodderly and Barlow, 1970).

A final problem is that the fraction of the nerve which was cut in the hemisection experiment exceeded the fraction of the tectal surface with low density of silver grains. There are several possible reasons for this, but none are satisfactory. First, the disparity might reflect the variable planimetric density of fibers in the nerve (Fig. 4A). This can be ruled out by the observation that, even when the high density regions were sectioned (in those cases where peripheral tectum was free of grains), the discrepancy was still in evidence, contrary to expectation. A second possibility is that the terminal arbors of the retinal ganglion cells are so large that their overlap with the degenerating arbors masked the absence of the latter. There are no estimates of the extent of these arbors in fish, but in frogs, they are only a few hundred micrometers wide (George and Marks, 1974), not enough to account for the discrepancy here. A third explanation might lie in sprouting. If, in the 5 days between surgery and sacrifice, the fibers bounding the denervated region had sprouted, they might have partially filled it and produced the apparent discrepancy. This is an unlikely explanation, however, since partially denervated tectum (caused by retinal lesions) was not invaded by retinal terminals until months after the lesion (Schmidt et al., 1978). In summary, the size discrepancy remains a puzzle.

Nonmyelinated fibers. Gaze first reported that goldfish optic nerves include a relatively few nonmyelinated fibers, restricted to one or two bundles (Gaze, 1970, p. 131). This same situation was noted also in ribbon-shaped optic nerves (Tapp, 1973; Scholes, 1979). The possibility that the nonmyelinated fibers might be the new ones was raised first by Dawnay (1979b), Scholes (1979), and Easter et al. (1979). Although the data presented above surely support this idea, there is an alternative explanation: the nonmyelinated fibers might be efferents from the brain (Sandeman and Rosenthal, 1974; Schmidt, 1979). However, this explanation can be ruled out by several observations. The optic nerves of the large goldfish lacked significant numbers of nonmyelinated fibers (Table I), but they contained efferents (Schmidt, 1979). Moreover, Witkovsky (1971) found that the efferent fibers were myelinated in the retina. Another reason for doubt relates to conduction velocity. The tiny nonmyelinated fibers should have the slowest conduction velocity in the nerve, but the efferents are the most rapidly conducting fibers in the nerve (Schmidt, 1979) and are, therefore, probably large and myelinated. We conclude that the nonmyelinated fibers are not efferents. They are most likely the recently formed fibers soon to be myelinated. The largest fish lacked them, presumably because the production of ganglion cells slowed down, because the rate of myelination speeded up, or both.

Numbers of fibers. We found that the optic nerves of small goldfish, approximately 1 year old, contained about 120,000 fibers and those of large goldfish, 5 years old, had about 180,000 . These numbers are considerably higher than that reported by Gaze (1970, p. 131) - 68,000. Gaze did not give the size or age of his goldfish; we suggest that they were younger and smaller than ours. In the only other electron microscopic count of optic nerve fibers in a teleost, Tapp (1974) found 200,000 in Eugerres plumieri, somewhat more than we found in even our largest goldfish. Since Tapp examined only a single size of Eugerres, the difference may be attributed to either species or age.

The demonstration that new fibers are added to the nerve continually confirms and extends earlier studies on retinal growth. Especially pertinent are the papers of Johns and Easter (1977) and Kock and Reuter (1978), which included estimates of the numbers of ganglion cells in goldfish and the congeneric crucian carp. Although both papers reported an increase, they disagreed on its magnitude, with the earlier report claiming the larger maximum. We might dismiss this as a species difference or a difference due to age and environmental history except that the number of fibers that we found in the large goldfish is closer to the number of ganglion cells found by Kock and Reuter in crucian carp. Therefore, we must attempt to reconcile the discrepancy between these two earlier studies. The most obvious cause is that the method of histological preparation, and consequently cell-counting technique, differed. Kock and Reuter prepared whole mounts and stained them with methylene blue; Johns and Easter used radial sections of paraffinembedded eyes. The latter method resulted in a larger variance in estimated total ganglion cell number among fish of similar size. This was due presumably to the nonrandom distribution of ganglion cells as Kock and 
Reuter later pointed out. Another problem was that of distinguishing ganglion cells from glial cells. Johns has repeated the original study recently using better histological methods (glycomethylacrylate embedding, thinner sections, and retrograde labeling by HRP to identify ganglion cell somata) and a better sampling strategy. She has concluded that a large glial cell in the ganglion cell layer may have been scored in the earlier study, thus yielding systematically higher estimates. When this cell is omitted, the numbers of ganglion cells are closer to those reported by Kock and Reuter (1978) and to the numbers of axons reported here. The earlier estimates of the numbers of other retinal cell types have been confirmed in this recent study ( $P$. R. Johns, personal communication). In summary, the estimates of ganglion cell numbers closely match the estimates of axon numbers. There is probably one axon per cell, at least in the orbital portion of the nerve.

Conclusion. With one possible exception (the holocentrid studied by Schwassmann (1975)), axons in the optic nerves of all of the teleosts which have been studied are ordered by the pattern of retinal growth. Axons which grow out of the retina together cluster together in the optic nerve while also remaining near axons from similar regions of the retina. Does this ordering serve any function? Evidently order in the nerve is not essential to good visual function; cats have highly developed visual systems, but axons in their nerves seem to be quite scrambled (Horton et al., 1979; but see Mason et al., 1979). Indeed, our own work has shown that the distance between two axons in goldfish nerves can vary quite substantially. These results argue against the idea that the precision of the retinotectal map depends on precise order in the nerve (Horder and Martin, 1978). Nonetheless, during the very early stages of development, axons associate closely with others that originate nearby and segregate with these neighbors into particular parts of the nerve (Bodick and Levinthal, 1980). This orderly behavior may be very important in navigation by early axons, when they are few and the route has not been crossed yet. At later times, when the nerve and tract are well established, the ordered association of outgrowing axons may be less important in finding the route to the brain, but it may still be important in segregation within the brain. We have found that new axons grow preferentially into peripheral tectum; perhaps association with other axons destined for the same region aids all of them to find the way.

\section{References}

Attardi, D. G., and R. W. Sperry (1963) Preferential selection of central pathways by regenerating optic fibers. Exp. Neurol. 7: 46-64.

Bodick, N., and C. Levinthal (1980) Growing optic nerve fibers follow neighbors during embryogenesis. Proc. Natl. Acad. Sci. U. S. A. 77: 4374-4378.

Bunt, S. M. (1980) Evidence for a topographic arrangement of retinal axons within the teleost optic nerve. Invest. Ophthalmol. Vis. Sci. (Suppl.) 19: 2.

Bunt, S. M., and T. J. Horder (1978) Evidence for an orderly arrangement of optic axons in the central pathways of vertebrates and its implications for the formation and regeneration of optic projections. Soc. Neurosci. Abstr. 4: 468.
Dawnay, N. A. H. (1979a) Retinotopic architecture in goldfish optic pathway. J. Physiol. (Lond.) 289: 50-51P.

Dawnay, N. A. H. (1979b) 'Chronotopic' organization of goldfish optic pathway. J. Physiol. (Lond.) 296: 13-14P.

Easter, S. S., P. E. Kish, and S. S. Scherer (1979) Growth and development of the optic nerve in juvenile goldfish. Soc. Neurosci. Abstr. 5: 158.

Gaze, R. M. (1970) The Formation of Nerve Connections, Academic Press, New York.

Gaze, R. M., and P. Grant (1978) The diencephalic course of regenerating retinotectal fibres in Xenopus tadpoles. J. Embryol. Exp. Morphol. 44: 201-216.

George, S. A., and W. B. Marks (1974) Optic nerve terminal arborizations in the frog: Shape and orientation inferred from electrophysiological measurements. Exp. Neurol. 42: 467-482.

Horder, T. J., and K. A. C. Martin (1978) Morphogenetics as an alternative to chemospecificity in the formation of nerve connections. Symp. Soc. Exp. Biol. 32: 274-358.

Horton, J. C., M. M. Greenwood, and D. H. Hubel (1979) Nonretinotopic arrangements of fibres in cat optic tract. Nature 282: 720-722.

Jacobson, M., and R. M. Gaze (1964) Types of visual response from single units in the optic tectum and optic nerve of the goldfish. Q. J. Exp. Physiol. 49: 199-209.

Jacobson, M., and R. M. Gaze (1965) Selection of appropriate tectal connections by regenerating optic nerve fibers in adult goldfish. Exp. Neurol. 13: 418-430.

Johns, P. R. (1977) Growth of the adult goldfish eye. III. Source of the new retinal cells. J. Comp. Neurol. 176: 343-358.

Johns, P. R., and S. S. Easter (1977) Growth of the adult goldfish eye. II. Increase in retinal cell number. J. Comp. Neurol. 176: 331-342.

Karnovsky, M. J. (1967) The ultrastructural basis of capillary permeability studied with peroxidase as a tracer. J. Cell Biol. 35: 213-236.

Kock, J. H., and T. Reuter (1978) Retinal ganglion cells in the crucian carp (Carassius carassius). 1. Size and number of somata in eyes of different size. J. Comp. Neurol. 179: 535548.

Leghissa, S. (1955) La struttura microscopica e la citoarchitettonica del tetto ottico dei pesci teleostei. Z. Anat. Entwicklungsgesch. 118: 427-463.

Levinthal, F., and C. Levinthal (1980) Development of retinotectal connections. Soc. Neurosci. Abstr. 6: 293.

Marotte, L. R. (1980) Goldfish retinotectal system: Continuing development and synaptogenesis. J. Comp. Neurol. 193: 319334.

Mason, C. A., E. H. Polley, and R. W. Guillery (1979) Retinotopic organization of axons in the optic nerve and tract of normal and Siamese cats. Soc. Neurosci. Abstr. 5: 795.

Meyer, R. L. (1977) Eye-in-water electrophysiological mapping of goldfish with and without tectal lesions. Exp. Neurol. 56: 23-41.

Meyer, R. L. (1978) Evidence from thymidine labelling for continuing growth of retina and tectum in juvenile goldfish. Exp. Neurol. 59: 99-111.

Müller, H. (1952) Bau und Wachstum der Netzhaut des Guppy (Lebistes reticulatus). Zool. Jb. 63: 275-324.

Murray, M. (1976) Regeneration of retinal axons into the goldfish optic tectum. J. Comp. Neurol. 168: 175-196.

Neale, J. H., E. A. Neale, and B. W. Agranoff (1972) Radioautography of the optic tectum of the goldfish after intraocular injection of $\left({ }^{3} \mathrm{H}\right)$ proline. Science 176: 407-410.

Rusoff, A. C. (1979) Axon distribution in the optic nerve is not random. Invest. Ophthalmol. Vis. Sci. (Suppl.) 18: 18.

Rusoff, A. C., and S. S. Easter (1979) Order in the optic nerve of goldfish. Soc. Neurosci. Abstr. 5: 176.

Rusoff, A. C., and S. S. Easter (1980) Order in the optic nerve 
of goldfish. Science 208: 311-312.

Sandeman, D. C., and N. P. Rosenthal (1974) Efferent axons in the fish optic nerve and their effect on retinal ganglion cells. Brain Res. 68: 41-54.

Schmidt, J. T. (1979) The laminar organization of optic nerve fibers in the tectum of goldfish. Proc. R. Soc. Lond. (Biol.) 205: 287-306.

Schmidt, J. T., C. M. Cicerone, and S. S. Easter (1978) Expansion of the half retinal projection to the tectum in goldfish: An electrophysiological and anatomical study. J. Comp. Neurol. 177: 257-278.

Scholes, J. H. (1979) Nerve fibre topography in the retinal projection to the tectum. Nature 278: 620-624.

Schwassmann, H. O. (1975) Central projections of the retina and vision. In Vision in Fishes, M. A. Ali, ed., pp 113-126, Plenum, New York.

Schwassmann, H. O., and L. Kruger (1965) Organization of the visual projection upon the optic tectum of some freshwater fish. J. Comp. Neurol. 124: 113-126.

Snodderly, D. M., and R. B. Barlow (1970) Projection of the lateral eye of Limulus to the brain. Nature 227: 284-286.

Stell, W. K., and P. Witkovsky (1973) Retinal structure in the smooth dogfish, Mustelus canis: General description and light microscopy of giant ganglion cells. J. Comp. Neurol. 148: 1-32.

Tapp, R. L. (1973) The structure of the optic nerve of the teleost, Eugerres plumieri. J. Comp. Neurol. 150: 239-252.

Tapp, R. L. (1974) Axon numbers and distribution, myelin thickness, and the reconstruction of the compound action potential of the optic nerve of the teleost, Eugerres plumieri. J. Comp. Neurol. 153: 267-274.

Witkovsky, P. (1971) Synapses made by myelinated fibers running to teleost and elasmobranch retinas. J. Comp. Neurol. 142: 205-222. 